\title{
Increased VWF and Decreased ADAMTS-13 in COVID-19: Creating a Milieu for (Micro)Thrombosis
}

\author{
Emmanuel J. Favaloro, PhD, FFSc, RCPA ${ }^{1,2(0)}$ Brandon Michael Henry, MD ${ }^{3}$ Giuseppe Lippi, MD ${ }^{4(0)}$ \\ 1 Haematology, Sydney Centres for Thrombosis and Haemostasis, \\ Institute of Clinical Pathology and Medical Research (ICPMR), NSW \\ Health Pathology, Westmead Hospital, Westmead, New South \\ Wales, Australia \\ 2 School of Biomedical Sciences, Charles Sturt University, Wagga \\ Wagga, New South Wales, Australia \\ ${ }^{3}$ Cardiac Intensive Care Unit, The Heart Institute, Cincinnati \\ Children's Hospital Medical Center, Ohio \\ ${ }^{4}$ Section of Clinical Biochemistry, University of Verona, Verona, Italy \\ Address for correspondence Emmanuel J. Favaloro, PhD, FFSc, RCPA, \\ Department of Haematology, Institute of Clinical Pathology and \\ Medical Research (ICPMR), Westmead Hospital, Westmead, \\ New South Wales, 2145, Australia \\ (e-mail: emmanuel.favaloro@health.nsw.gov.au). \\ Semin Thromb Hemost 2021;47:400-418.
}

\section{Abstract}

\section{Keywords}

- von Willebrand factor

- ADAMTS-13

- COVID-19

- thrombosis von Willebrand factor (VWF) is a large adhesive multimeric protein involved in hemostasis. The larger the size (or number of VWF multimers), the greater the functionality of the protein. A deficiency or defect of VWF can lead to von Willebrand disease (VWD) and cause bleeding. Conversely, an increase in VWF may create an environment that promotes thrombosis. ADAMS-13 (a disintegrin and metalloproteinase with a thrombospondin type 1 motif, member 13), sometimes called VWF-cleaving protease, is primarily responsible for controlling the size of VWF. The most severe deficiency ( $<10 \%$ of normal levels) of ADAMTS13 arises in thrombotic thrombocytopenic purpura, a condition characterized by the presence of ultralarge VWF and clinically resulting in enhanced risk of thrombosis. However, ADAMTS-13 deficiency may result from other pathological processes. Of relevance is the recent finding that COVID-19 (coronavirus disease 2019) is associated with both increased levels and activity of VWF as well as generally decreased (or occasionally normal) activity levels of ADAMTS-13. Thus, in COVID-19 there is an alteration in the VWF/ADAMTS-13 axis, most often described by increased VWF/ADAMTS-13 ratio (or reduced ADAMTS-13/VWF ratio). COVID-19 is also associated with high prothrombotic risk. Thus, the imbalance of VWF and ADAMTS-13 in COVID-19 may be providing a milieu that promotes (micro) thrombosis, in a clinical picture resembling a secondary thrombotic microangiopathy in some patients. This review therefore assesses the literature on VWF, ADAMTS-13, and COVID-19. Whenever reported in COVID-19, VWF has always been identified as raised (compared with normal reference ranges or control populations). Reports have included VWF level (i.e., VWF antigen) and in some cases one or more VWF "activity" (e.g., collagen binding; platelet glycoprotein Ib [GPIb] binding, using ristocetin cofactor or more modern versions including VWF:GPIbR [recombinant] and VWF:GPIbM [mutant]). Whenever reported, ADAMTS-13 has been reported as "normal" or reduced; however, it should be recognized that "normal" levels may still identify a relative reduction in individual cases. Some reports also discuss the raised VWF/ADAMTS-13 (or reduced ADAMTS-13/VWF) ratio, but very few provide actual numerical data. published online April 26, 2021
Issue Theme Maintaining Hemostasis and Preventing Thrombosis in COVID-19 -Part II; Guest Editors: Emmanuel J. Favaloro, PhD, FFSc (RCPA) and Giuseppe Lippi, MD. (c) 2021. Thieme. All rights reserved. Thieme Medical Publishers, Inc., 333 Seventh Avenue, 18th Floor, New York, NY 10001, USA
DOI https://doi.org/ 10.1055/s-0041-1727282. ISSN 0094-6176. 
von Willebrand factor (VWF) is a large adhesive multimeric protein involved in hemostasis. The larger the size (or number of VWF multimers), the greater the functionality of the protein. ${ }^{1}$ A deficiency or defect of VWF can lead to von Willebrand disease (VWD) and cause bleeding. ${ }^{2}$ Conversely, an increase in VWF may cause thrombosis. ${ }^{3}$ Although an increase in VWF per se may be associated with thrombosis, it is an increase in the larger VWF protein moieties (sometimes called high-molecular-weight [HMW] VWF) that are more likely to provide a milieu conducive to thrombosis. The VWF cleaving protease ADAMTS-13 (a disintegrin and metalloproteinase with a thrombospondin type 1 motif, member 13) is primarily responsible for controlling the size of plasma VWF, as this enzyme proteolytically cleaves VWF multimers into smaller moieties, less able to promote thrombus formation. ${ }^{4}$

The most severe deficiency of ADAMTS- 13 arises in thrombotic thrombocytopenic purpura (TTP), ${ }^{4}$ a disorder characterized by levels of ADAMTS- 13 less than $10 \%$ of normal, with consequent occurrence of ultralarge forms of VWF. Not unsurprising, then, is that thrombosis is a key feature of TTP. However, a relative ADAMTS-13 deficiency can arise in a variety of pathophysiological states, including secondary microangiopathies. ${ }^{5}$

Most relevant for this review is that recent evidence has emerged that COVID-19 (coronavirus disease 2019), which is often associated with a high thrombotic risk, is characterized in many patients as an imbalance in the VWF/ADAMTS-13 "axis," in a clinical picture reported to closely resemble a secondary thrombotic microangiopathy. ${ }^{6}$ In summary, the most seriously affected patients with COVID-19 express a relatively high VWF/ADAMTS-13 ratio, which may thus create a milieu that promotes (micro)thrombosis. The current narrative review thus discusses findings reported to date regarding levels and activity of VWF and ADAMTS-13 in COVID-19.

\section{Methods}

We felt that a narrative review would suit our purpose best. The PubMed database (https://pubmed.ncbi.nlm.nih.gov) was therefore searched using various iterations of COVID-19 together with various iterations of ADAMTS-13 and VWF. An initial search was later updated to be current as of February 15, 2021. Of 100 total hits, we then excluded reviews, commentaries, single case reports, and articles found to be irrelevant to the topic, to achieve a core set of 38 articles that identified levels of VWF protein (VWF antigen [VWF:Ag]) and in some cases VWF "activity" and 22 articles that identified levels of ADAMTS-13 activity. Notably, 18 articles reported on VWF in COVID-19 (total = 1,324 COVID19 patients), ${ }^{7-24} 2$ reported on ADAMTS-13 and COVID-19 (total $=36$ COVID-19 patients), ${ }^{25,26}$ and 20 reported on both VWF and ADAMTS-13 in COVID-19 (total =1,197 COVID-19 patients) $^{27-47}$ (- Tables 1-3). Thus, data were available for VWF on more than 2,500 COVID-19 patients, and for ADAMTS-13 on more than 1,100 COVID-19 patients. VWF activity was reported as a variety of "activities," including
VWF:CB (collagen binding), VWF:RCo (ristocetin cofactor), VWF:GPIbR (glycoprotein Ib, recombinant), and VWF:GPIbM (glycoprotein Ib, mutant). In some articles, other "activities" were described, and in some reports VWF "activity" assays were otherwise unspecified ( $\mathbf{-}$ Tables $\mathbf{1}$ and $\mathbf{2}$ ). We restricted numerical reporting to studies containing more than five COVID-19 cases.

\section{VWF Level and Activity in COVID-19}

Most reports provided values for only VWF:Ag, albeit using a wide variety of methods (-Tables $\mathbf{1}$ and $\mathbf{2}$ ). Fewer reports provided values for VWF "activity," with a wide range of different activities reported; these in turn were also assessed using a wide variety of methods, sometimes unspecified (-Tables 1 and 2). When reported, VWF:Ag and various VWF activities were invariably increased compared with normal reference ranges (NRRs) or control groups ( - Tables 1 and 2). A few reports also provided values in different stages or severities of COVID-19. In general, higher levels of VWF:Ag or VWF activity were associated with more severe cases and nonsurvival.

\section{VWF:Ag}

-Figure 1A summarizes reports identifying the level of VWF: $\mathrm{Ag}$ in cases of COVID-19 compared with NRRs or controls, where more than five cases of COVID-19 were reported. Of interest, although the expected NRR for VWF:Ag would approximate 50 to $200 \mathrm{U} / \mathrm{dL}$ (or \% of normal), the literature on COVID-19 matches the general literature on VWF, and the reported NRR varied widely based on the individual study (and thus the methodology used; - Fig. 1A). Nevertheless, in general, the upper limit of normal was below $200 \mathrm{U} / \mathrm{dL}$ (or \%). In all studies, comprising various cohorts of COVID-19 patients, the reported median values among infected patients were always well above $200 \mathrm{U} / \mathrm{dL}$, and, indeed, so too were most of the reported lower limits of interquartile range (IQR) or standard deviation (SD) values (-Fig. 1A).

- Figure 1(B-D) shows additional data on VWF:Ag in COVID-19, where reports investigated a link between VWF level and "severity" of COVID-19. There was variability in the descriptions of COVID-19 severity, which included, for example, "critical" or intensive care unit (ICU) admission versus "noncritical" or non-ICU, and acute kidney injury (AKI) versus no AKI. Other comparisons were COVID-19 pneumonia versus non-COVID-19 pneumonia and COVID-19 VTE (venous thromboembolism) versus non-VTE COVID-19. A few reports were also available in regard to levels of VWF: Ag in survivors of COVID-19 versus nonsurvivors (-Fig. 1D). In general, the level of VWF:Ag is associated with COVID-19 severity. Thus, the highest levels of VWF:Ag were evident in those with "most severe" disease, as well as in nonsurvivors (-Fig. 1C, D).

\section{VWF Activity}

As noted earlier, a wide variety of VWF "activities" were reported in COVID-19 studies. The most frequent was for GPIb-binding (GPIbB) activity, using VWF:RCo, VWF:GPIbR, 


\begin{tabular}{|c|c|c|c|c|c|c|c|c|}
\hline 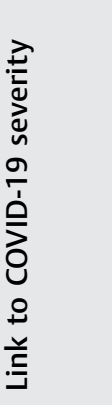 & 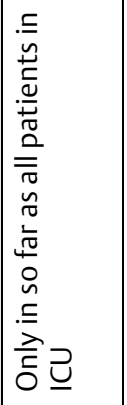 & 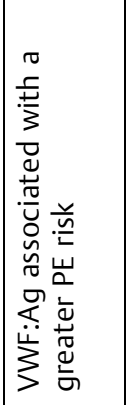 & 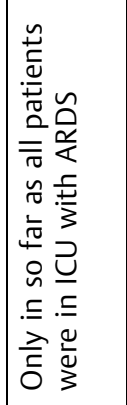 & 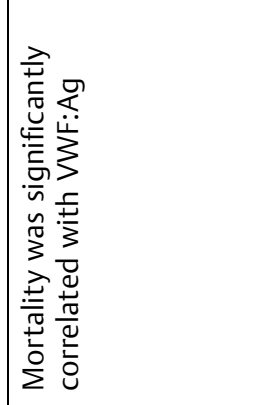 & 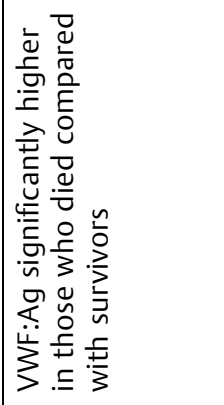 & 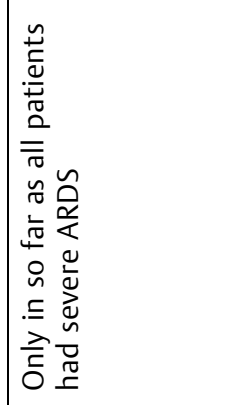 & 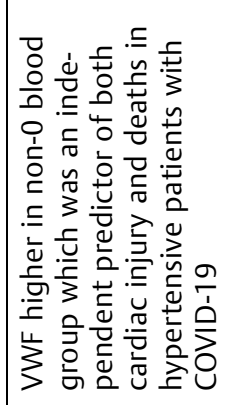 & 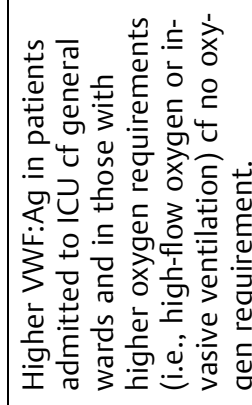 \\
\hline 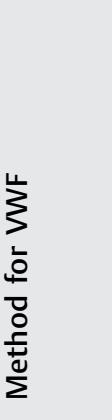 & 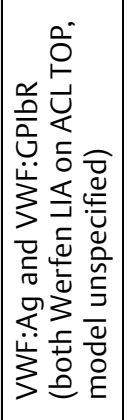 & 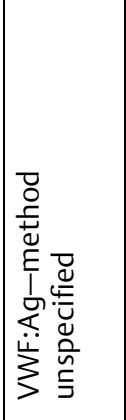 & 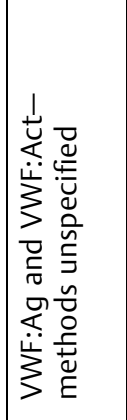 & 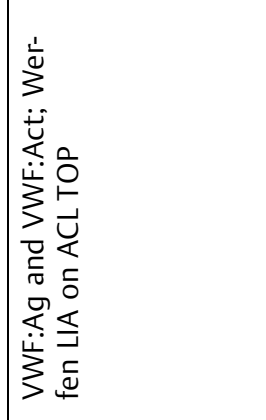 & 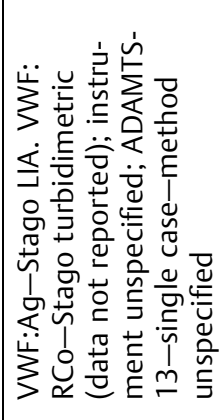 & 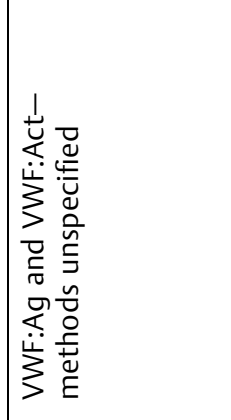 & 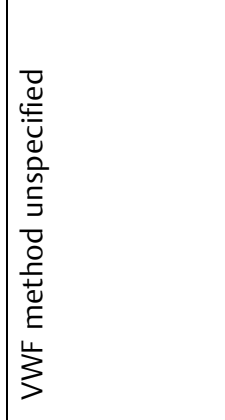 & 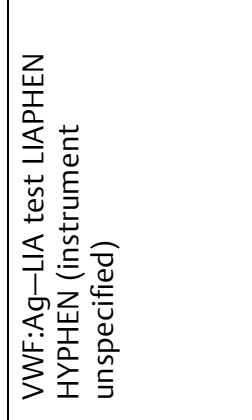 \\
\hline 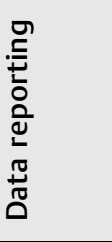 & 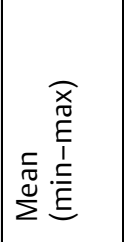 & 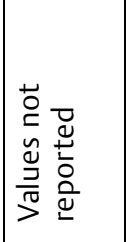 & 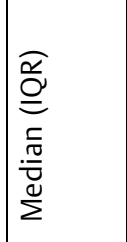 & 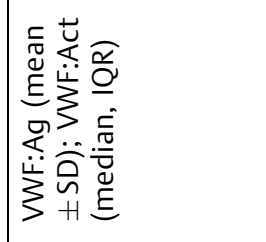 & 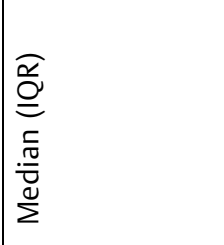 & 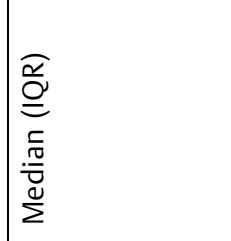 & 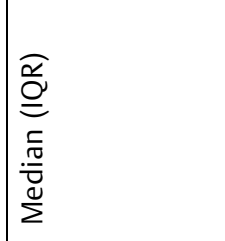 & $\begin{array}{l}0 \\
0 \\
+1 \\
\Sigma \\
\tilde{J} \\
\Sigma\end{array}$ \\
\hline 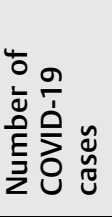 & $\mp$ & $\stackrel{\circ}{\circ}$ & $\stackrel{\circ}{\circ}$ & $\stackrel{\infty}{\wp}$ & $\stackrel{ \pm}{\sim}$ & $\stackrel{\infty}{\sim}$ & $\underset{0}{0}$ & 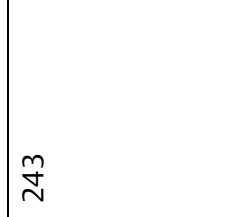 \\
\hline 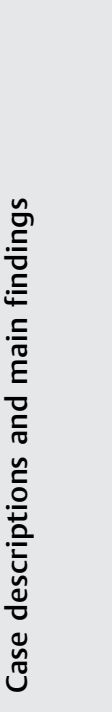 & 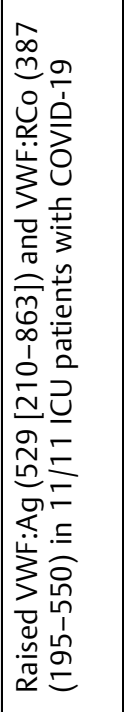 & 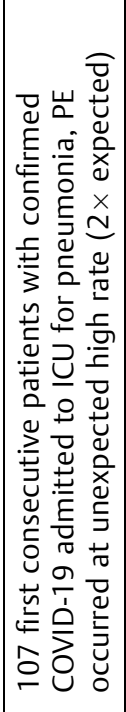 & 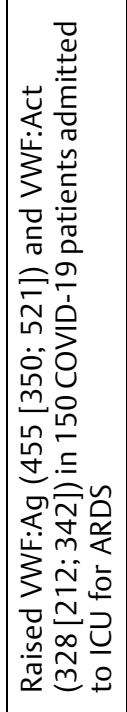 & 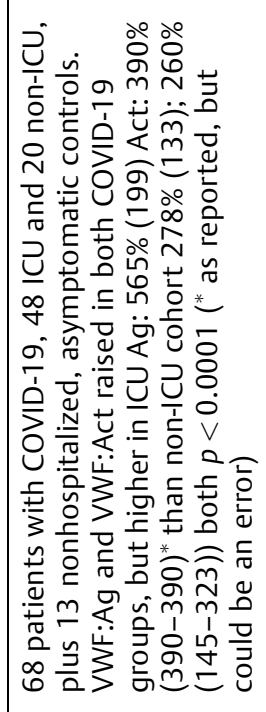 & 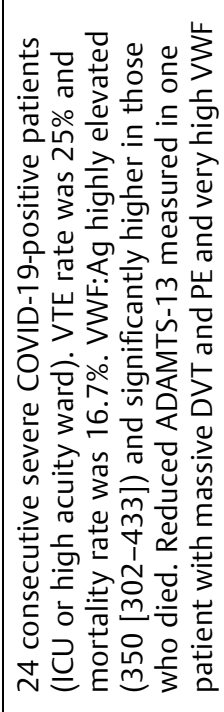 & 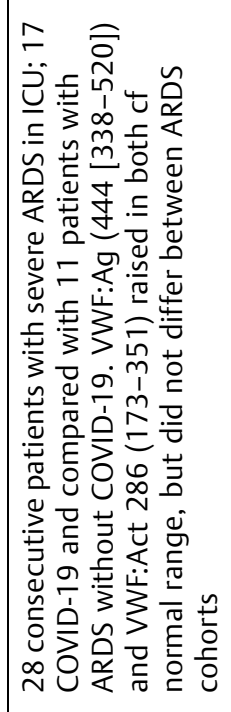 & 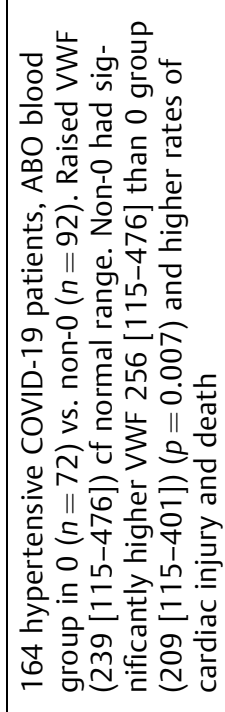 & 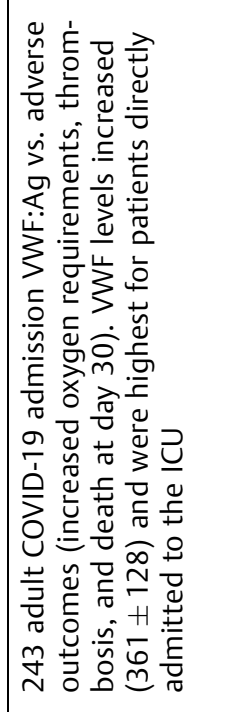 \\
\hline 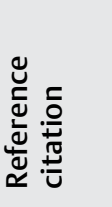 & 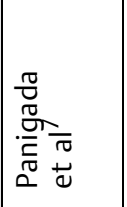 & 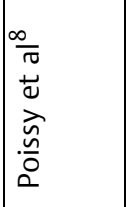 & $\begin{array}{l}\frac{\sigma}{\pi} \\
\frac{U}{0} \\
\tilde{E} \\
\frac{\tilde{E}}{0} \\
\frac{T}{I}\end{array}$ & 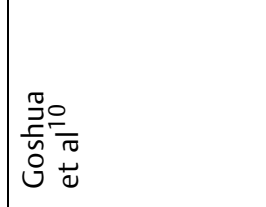 & 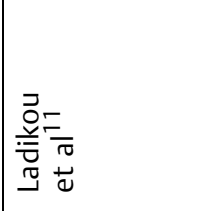 & 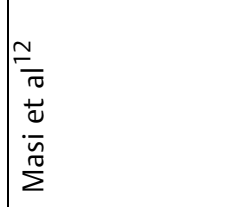 & 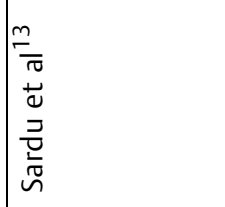 & 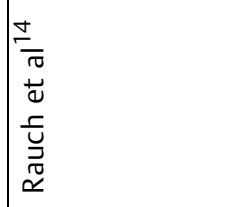 \\
\hline
\end{tabular}




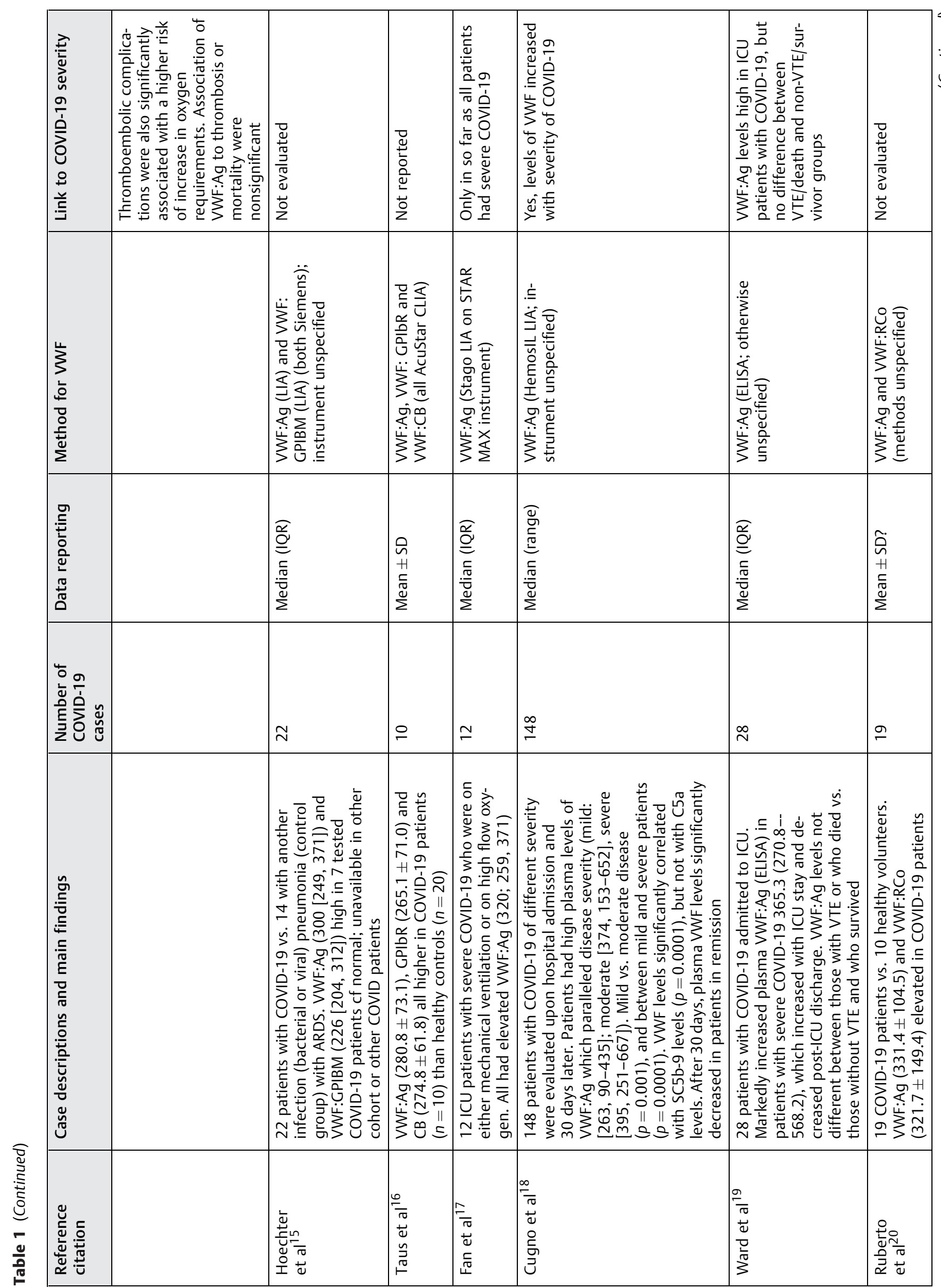




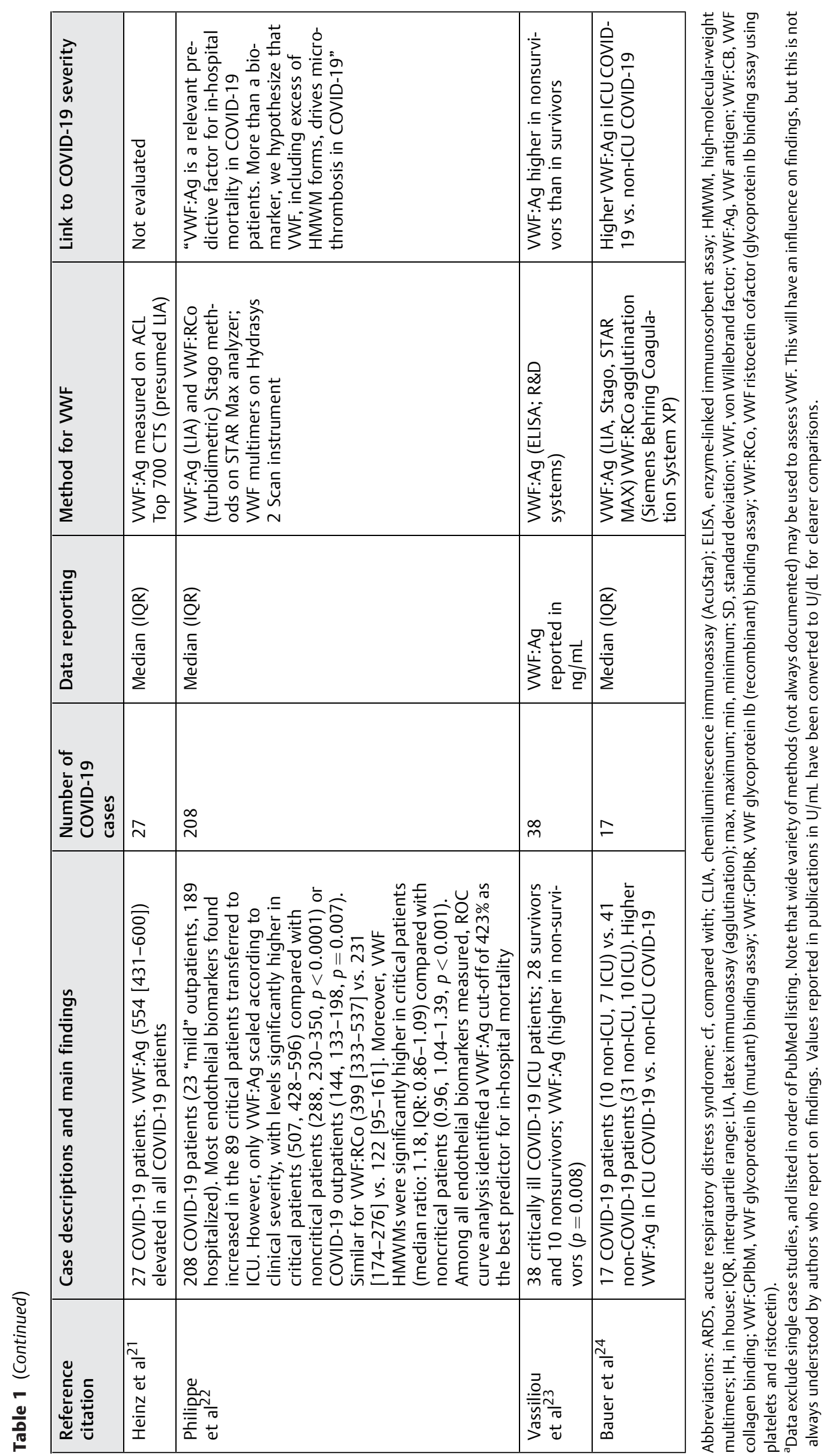


VWF, ADAMTS-13, COVID-19, and (Micro)Thrombosis Favaloro et al. 405

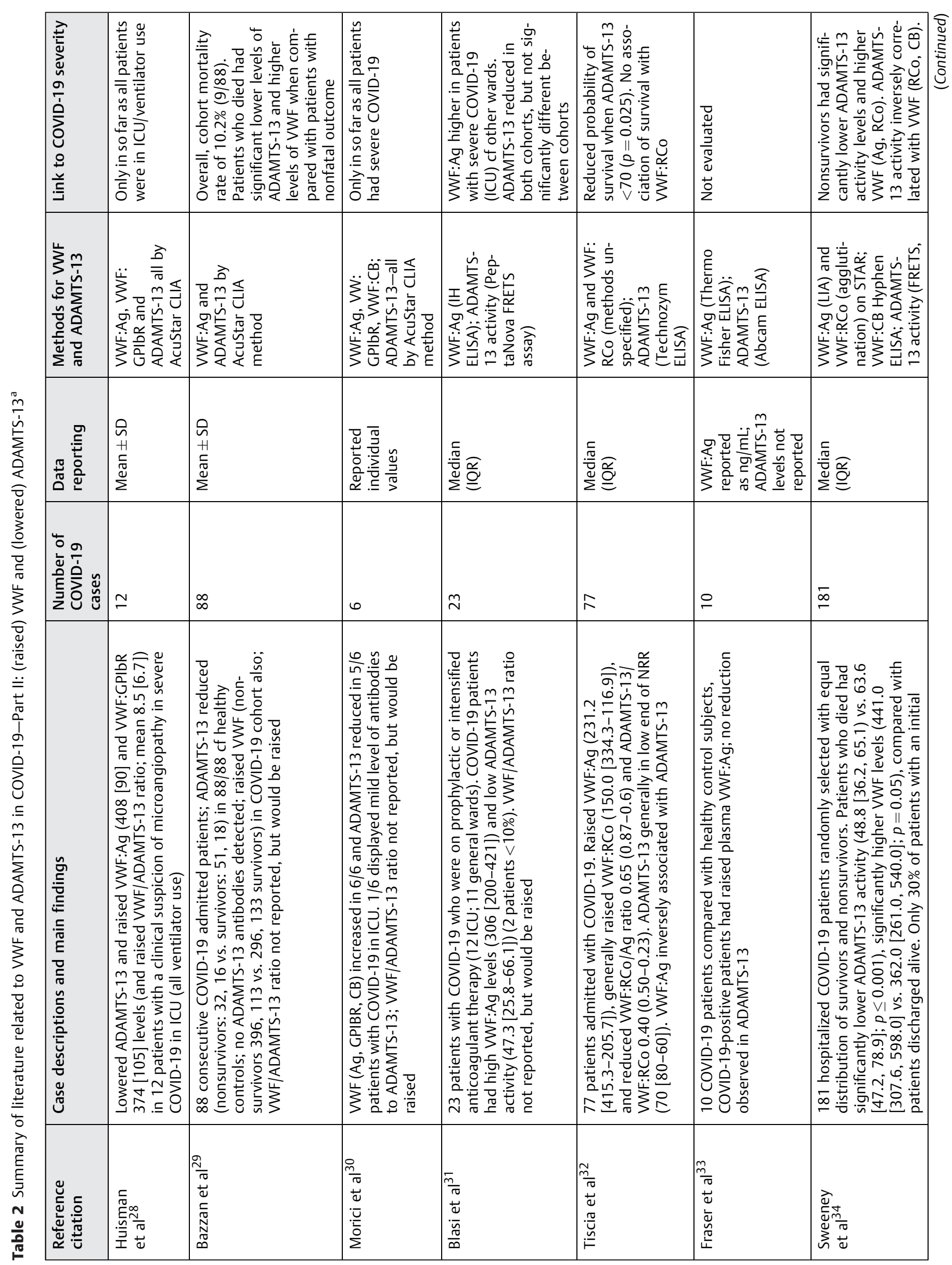




\begin{tabular}{|c|c|c|c|}
\hline 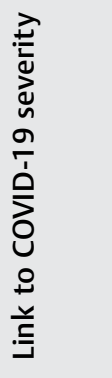 & 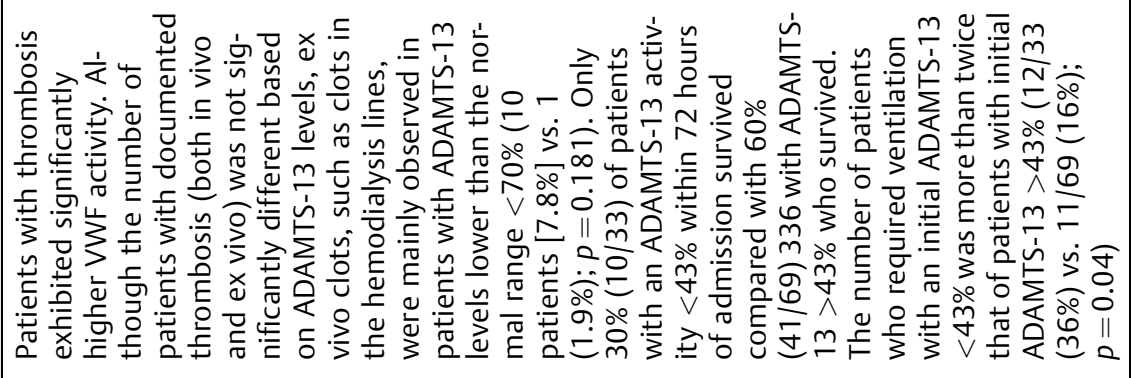 & 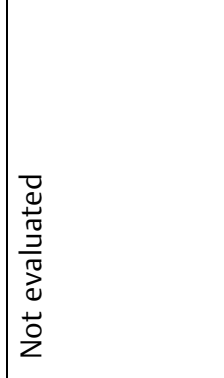 & 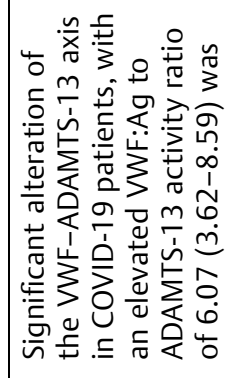 \\
\hline 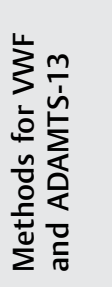 & 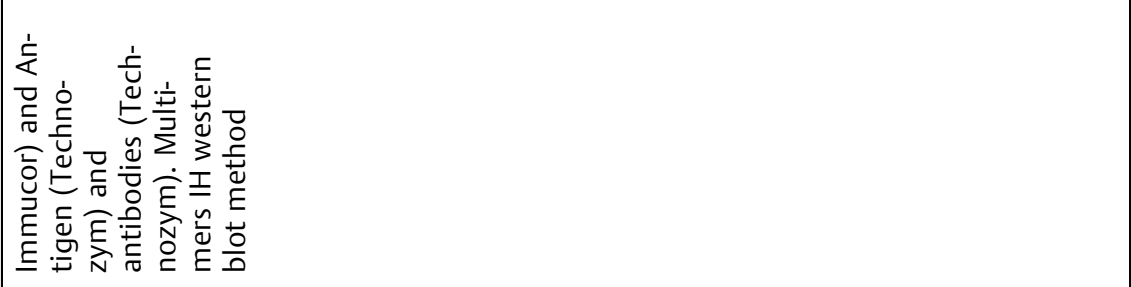 & 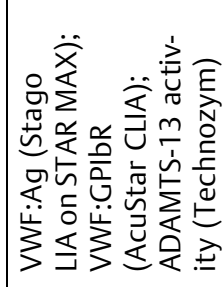 & 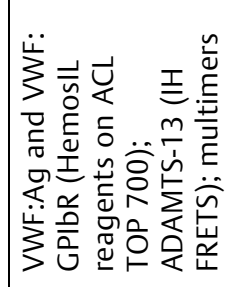 \\
\hline 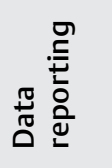 & & 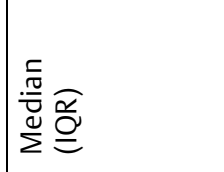 & 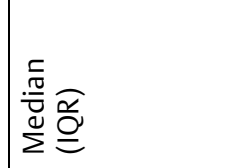 \\
\hline 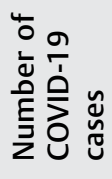 & & $\bar{N}$ & ㅇํ \\
\hline 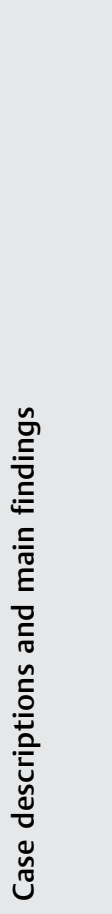 & 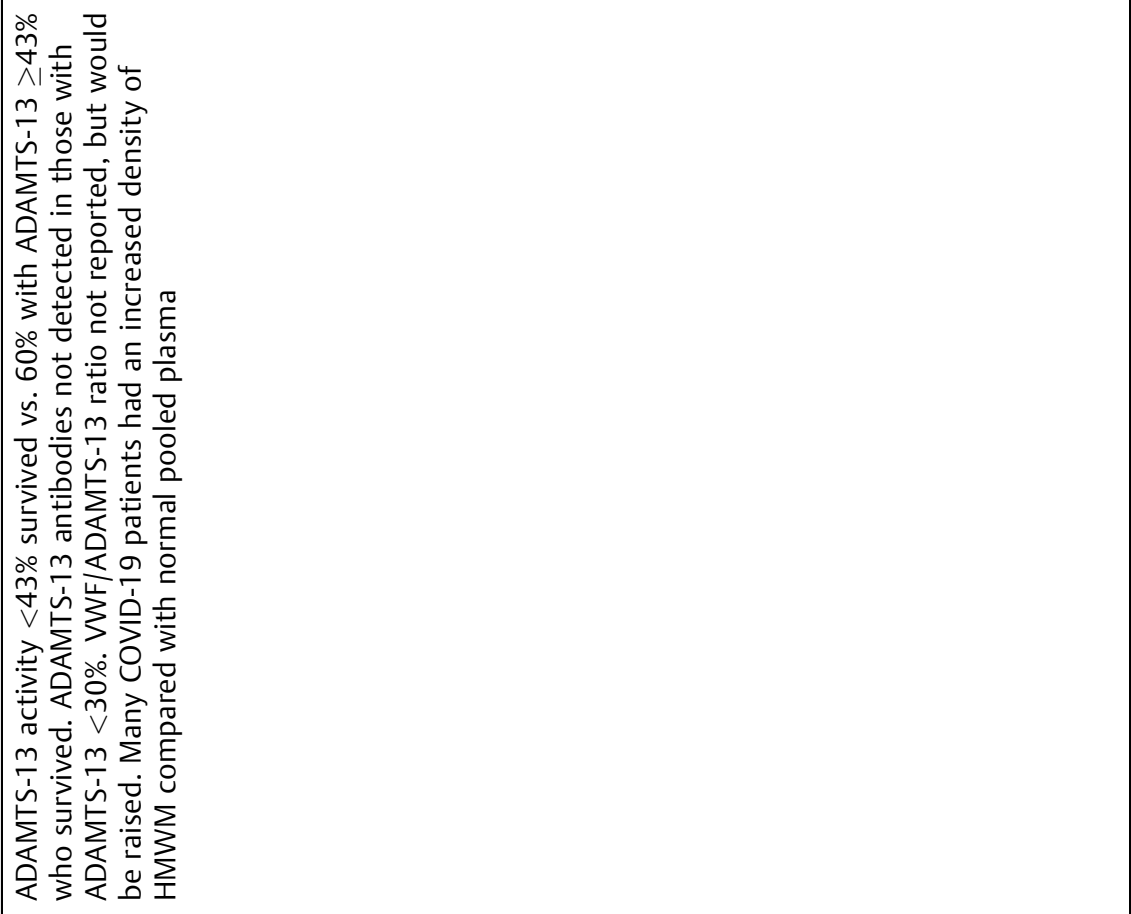 & 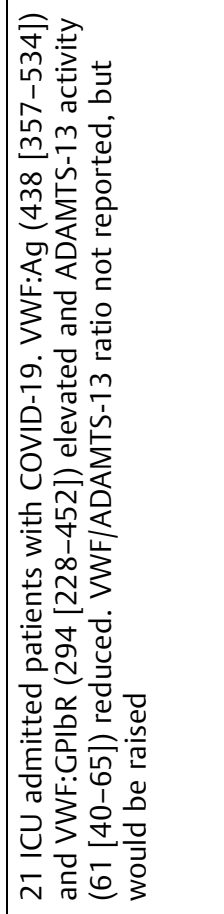 & 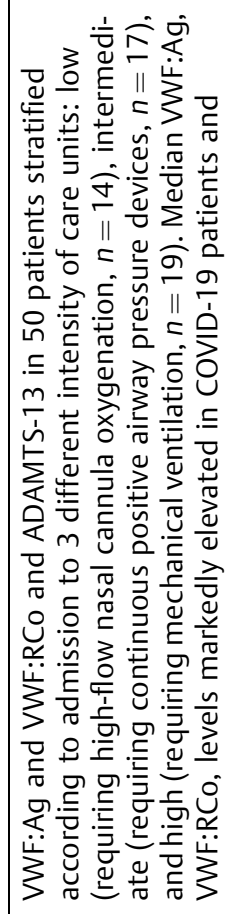 \\
\hline 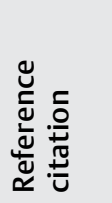 & & 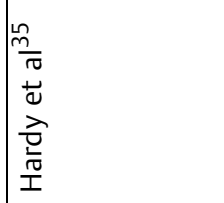 & 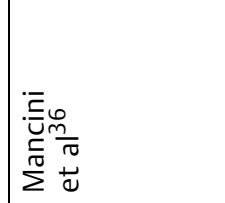 \\
\hline
\end{tabular}




\begin{tabular}{|c|c|c|c|c|c|c|}
\hline 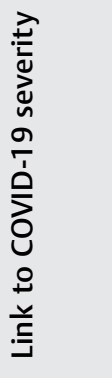 & 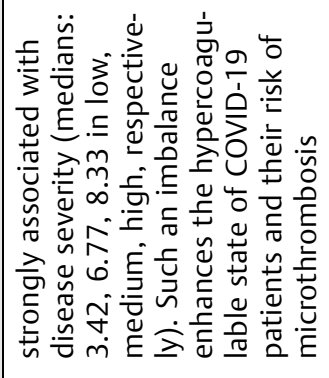 & 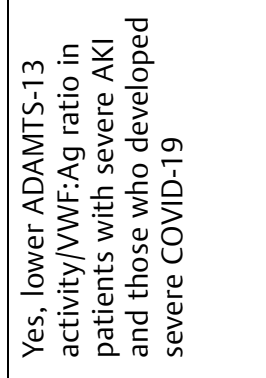 & 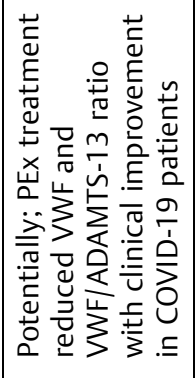 & 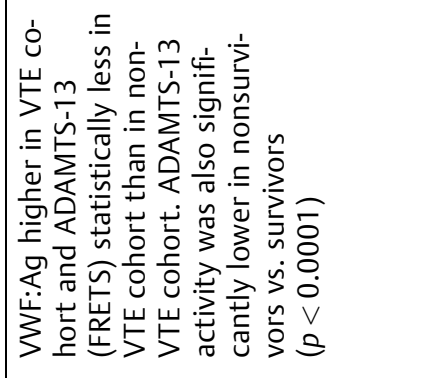 & 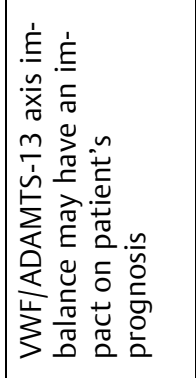 & 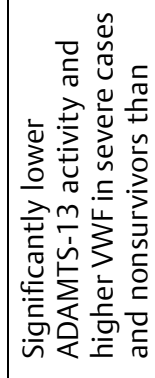 \\
\hline 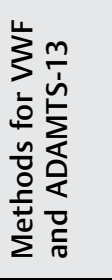 & 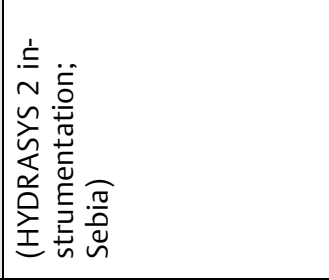 & 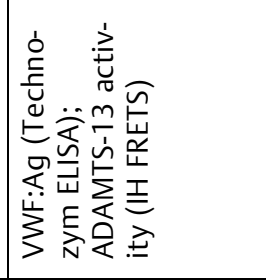 & 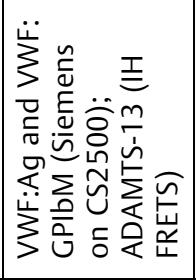 & 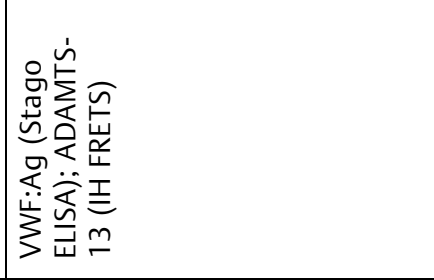 & 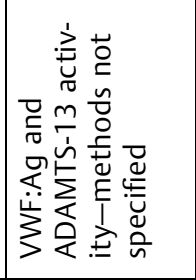 & 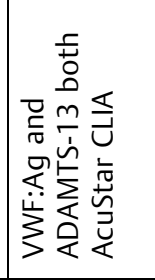 \\
\hline 焉 & & 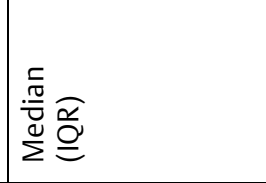 & 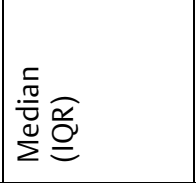 & 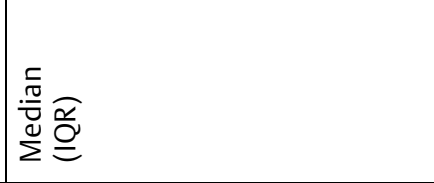 & 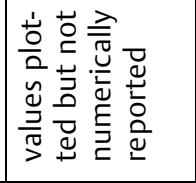 & 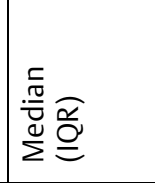 \\
\hline 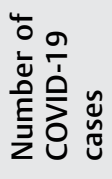 & & กี & $\wedge$ & $\stackrel{m}{m}$ & $\stackrel{\mathscr{F}}{\longleftarrow}$ & ○ \\
\hline 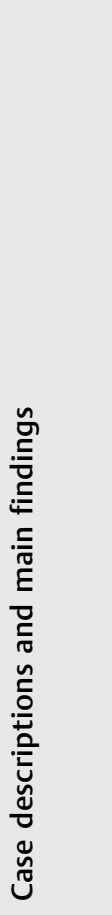 & 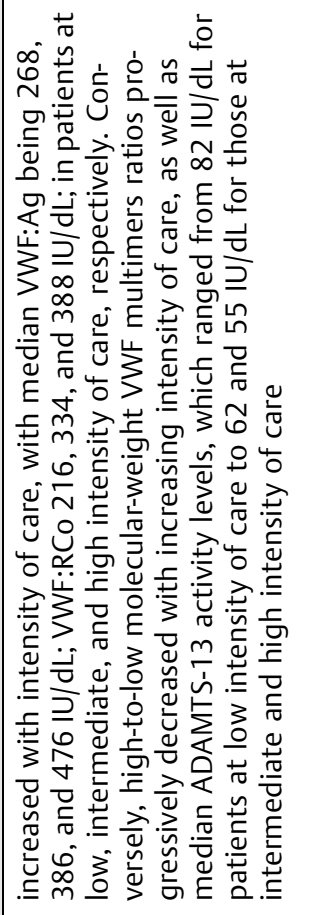 & 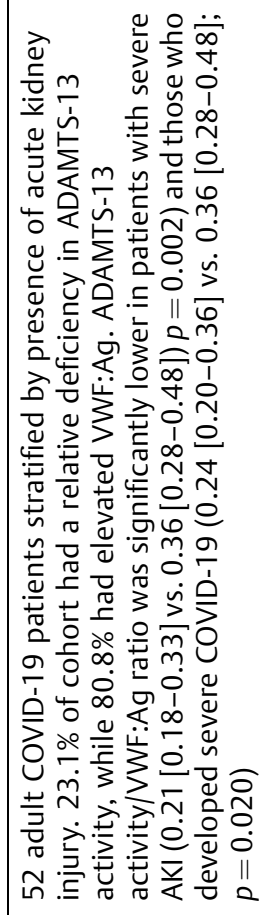 & 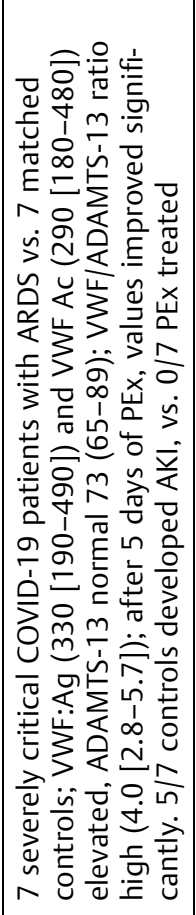 & 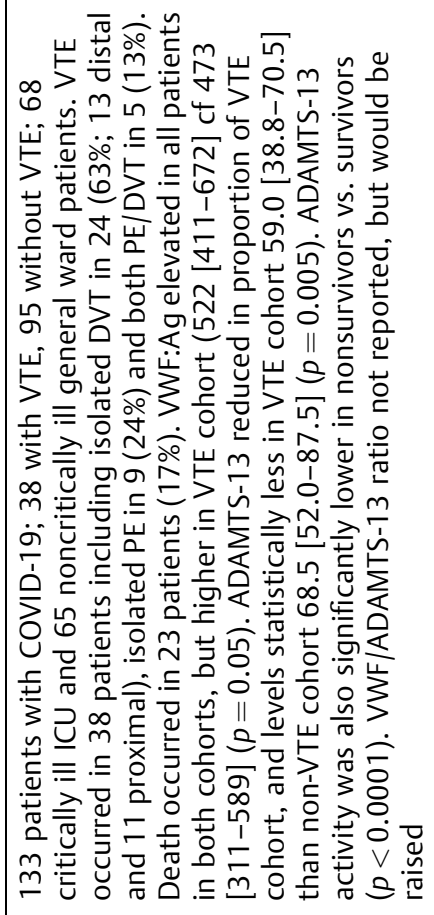 & 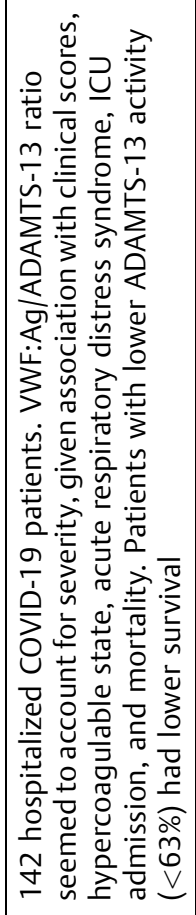 & 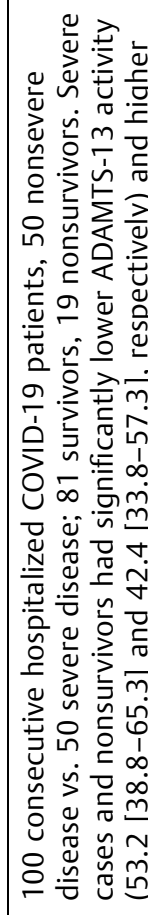 \\
\hline 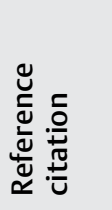 & & 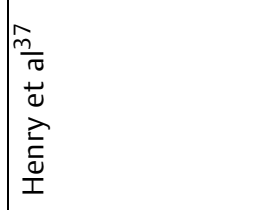 & 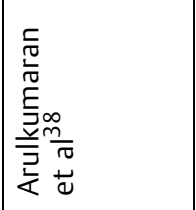 & 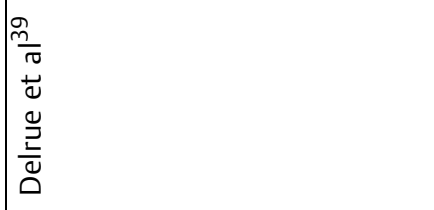 & 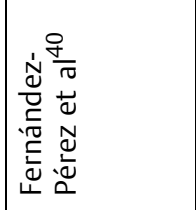 & 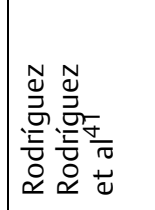 \\
\hline
\end{tabular}




\begin{tabular}{|c|c|c|c|c|c|c|}
\hline 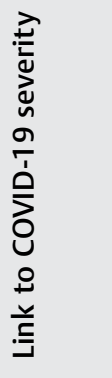 & 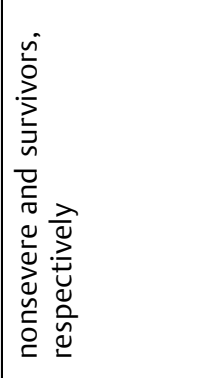 & 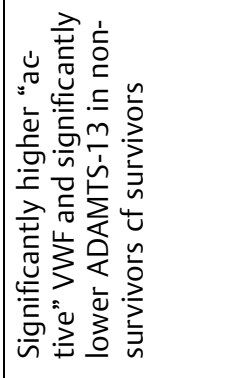 & 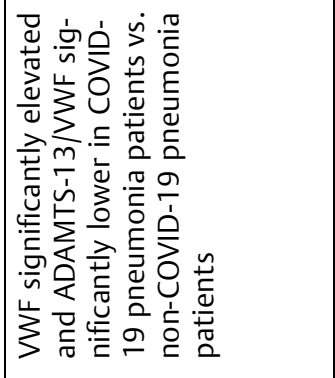 & 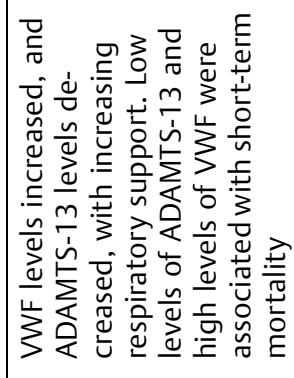 & 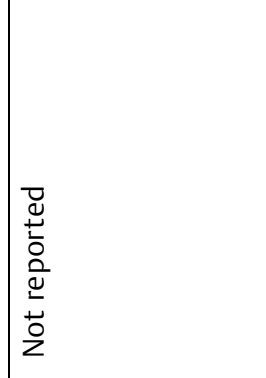 & 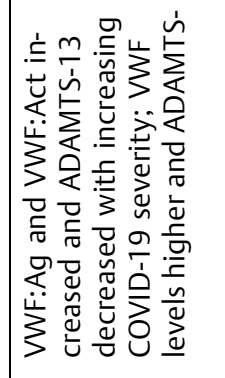 \\
\hline 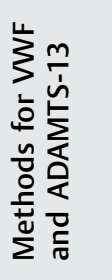 & & 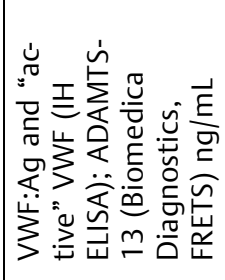 & 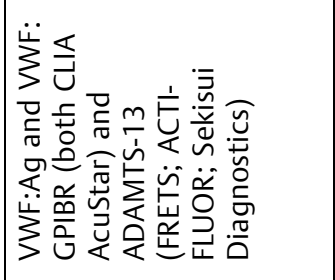 & 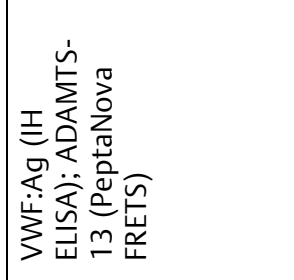 & 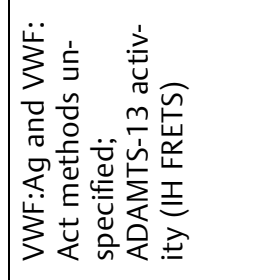 & 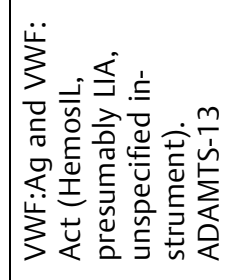 \\
\hline 胥 & & $\begin{array}{l}0 \\
\text { n } \\
+1 \\
\frac{1}{\pi} \\
\stackrel{0}{\Sigma}\end{array}$ & 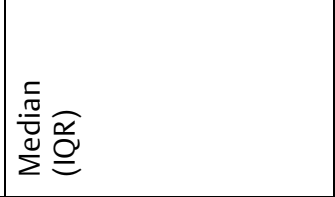 & 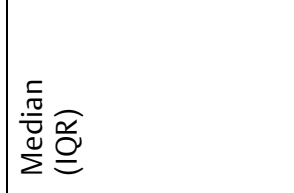 & 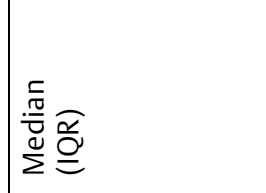 & 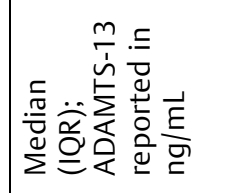 \\
\hline 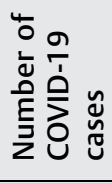 & & $\stackrel{0}{\circ}$ & $\stackrel{\circ}{\circ}$ & $\stackrel{\sim}{\circ}$ & $\approx$ & $\stackrel{\circ}{\circ}$ \\
\hline 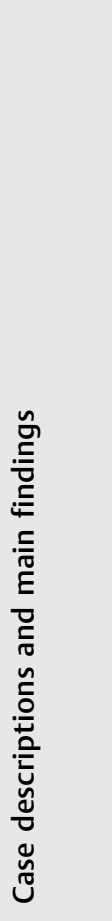 & 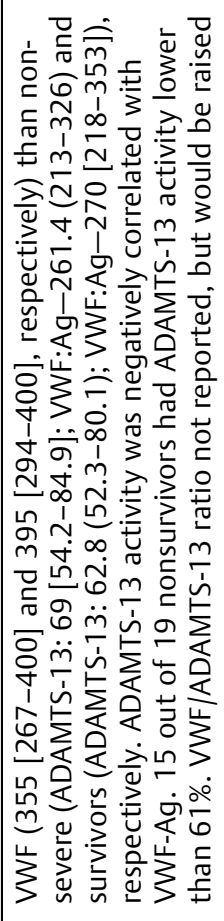 & 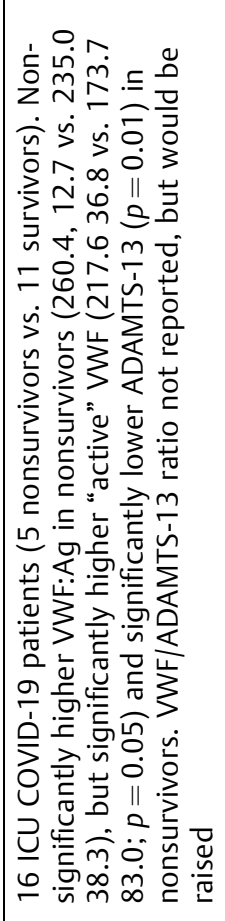 & 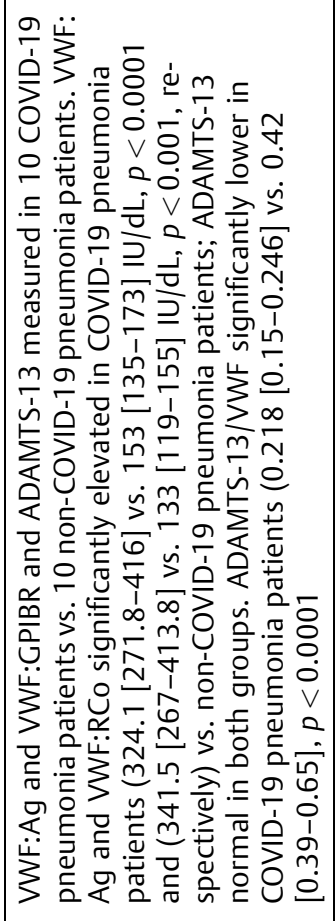 & 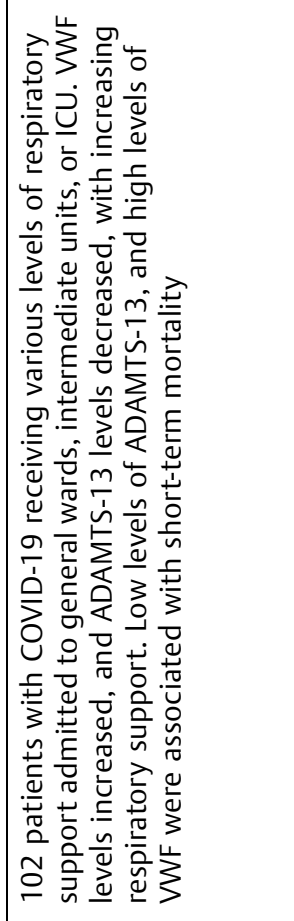 & 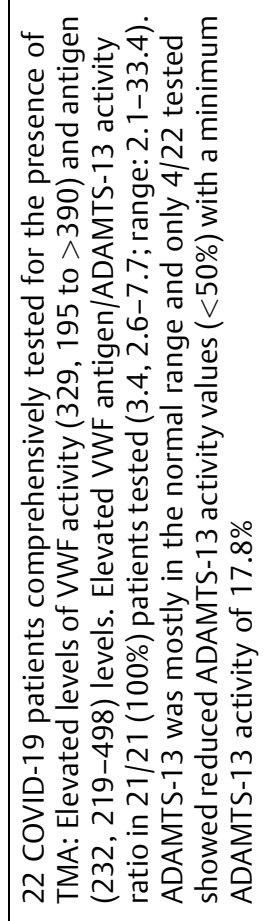 & 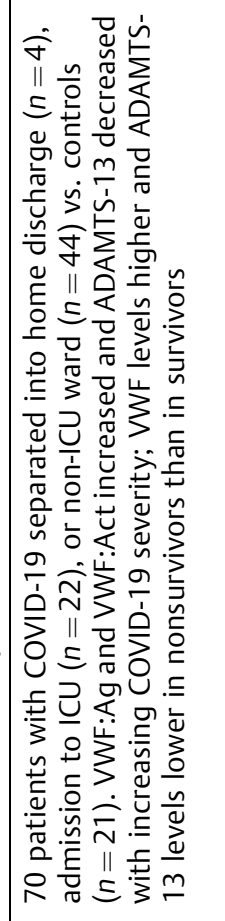 \\
\hline 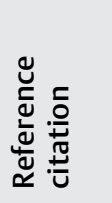 & & 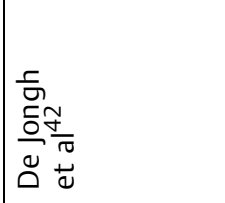 & 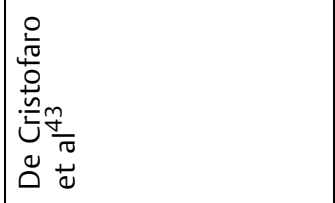 & 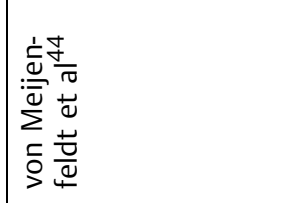 & 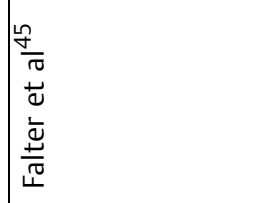 & 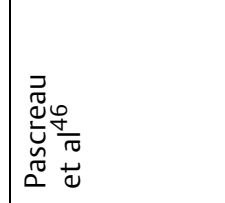 \\
\hline
\end{tabular}



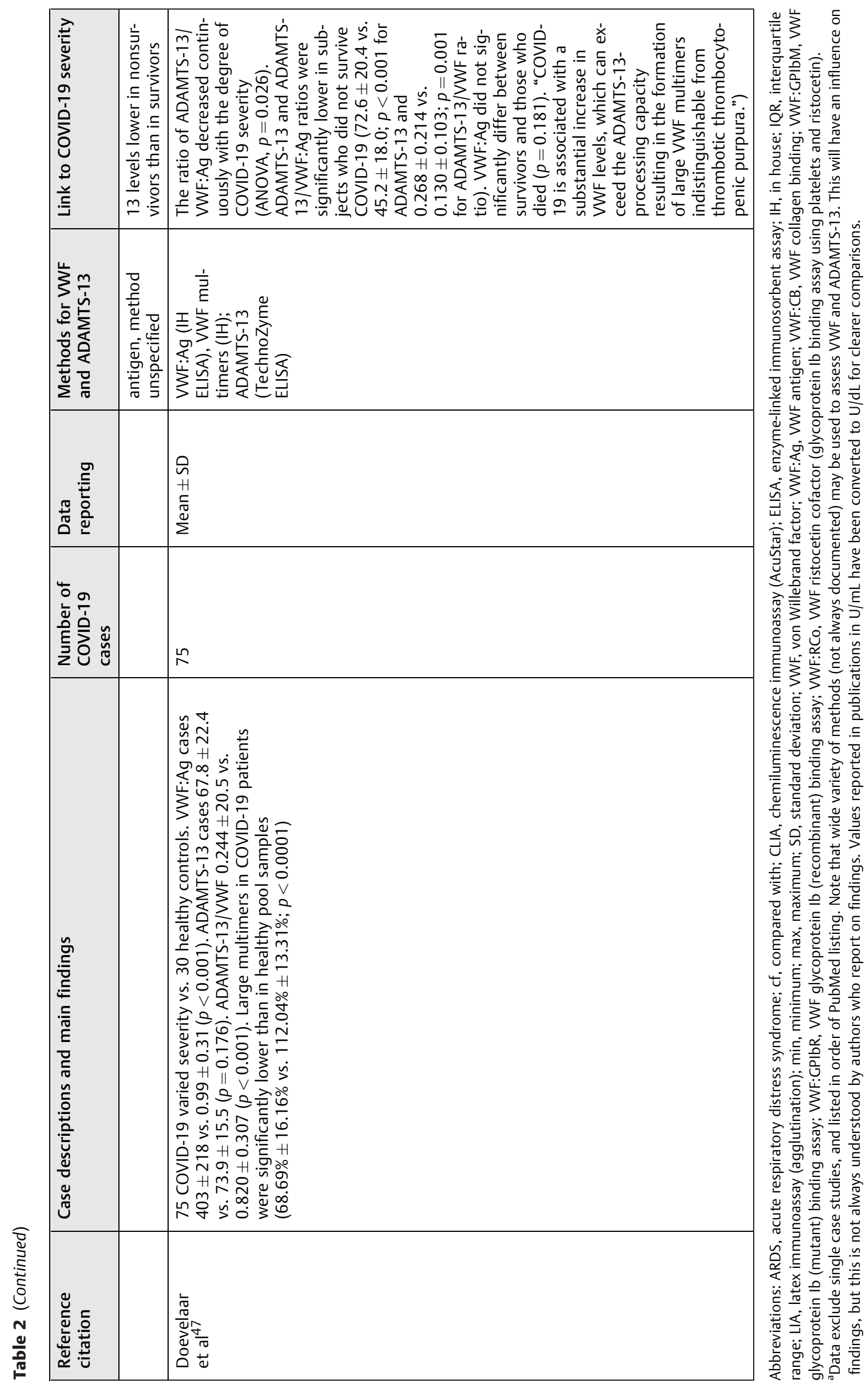
A. VWF:Ag (NRR vs COVID; $>5$ cases)

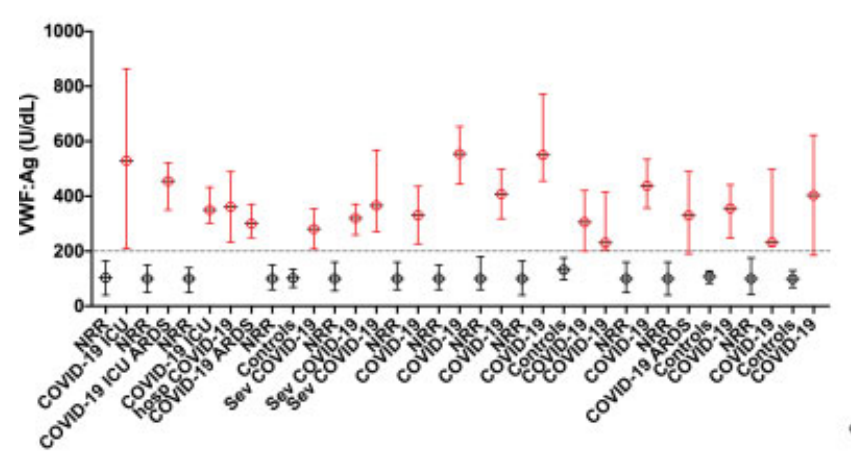

C. VWF:Ag (extended grades)

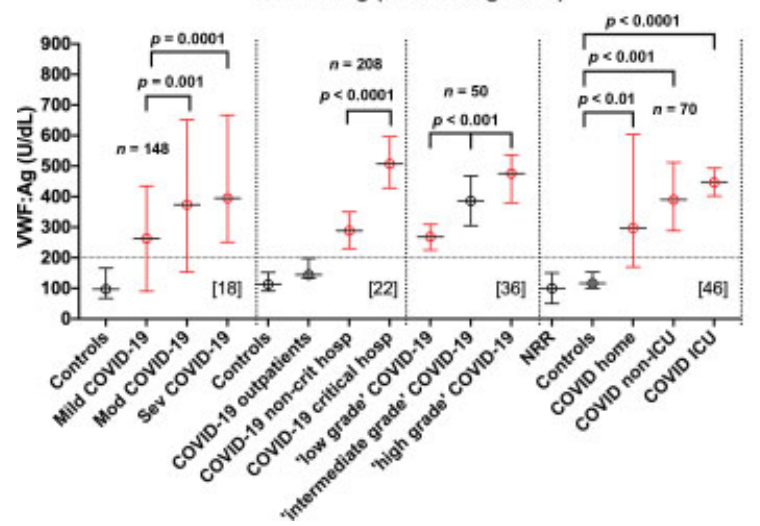

B. VWF:Ag (vs COVID 'grades')

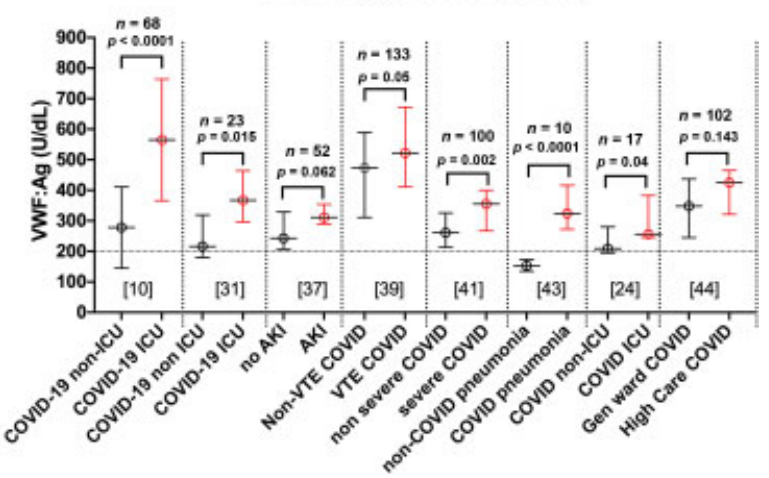

D. VWF:Ag (survival vs non-survival)

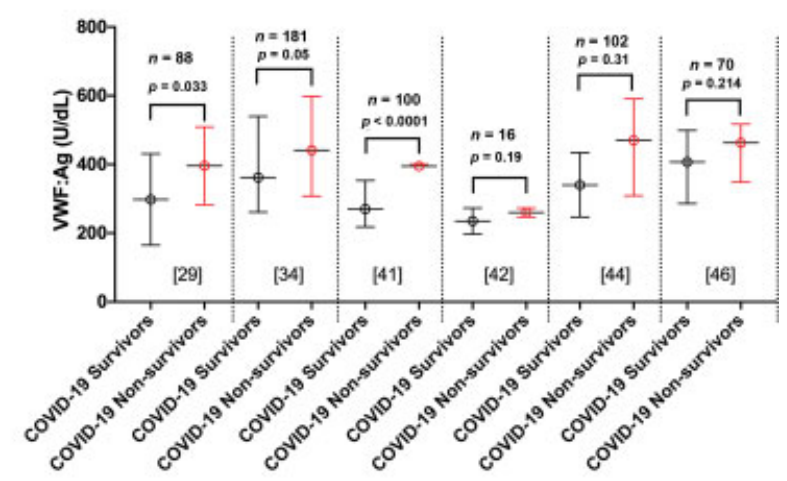

Fig. 1 Values of von Willebrand factor antigen (VWF:Ag) reported in the literature for cases of coronavirus disease (COVID)-19, where more than five cases were reported. (A) VWF:Ag (left Y-axis) in U/dL (=\% of normal) for various cohorts of COVID-19 (shown in red) versus normal reference ranges (NRRs) or control groups (shown in black). In general, NRRs were around 50-200 U/dL, whereas VWF:Ag in COVID-19 cases were invariably higher, with some cases reporting $>600 \mathrm{U} / \mathrm{dL}$. (B) VWF:Ag (left Y-axis) in U/dL (=\% of normal) for various cohorts of COVID-19 of differing "severity." (C) VWF:Ag (left Y-axis) in U/dL (=\% of normal) for various cohorts of COVID-19 of increasing "severity." (D) VWF:Ag (left Yaxis) in $\mathrm{U} / \mathrm{dL}$ ( $=\%$ of normal) for survivor versus nonsurvivor cohorts of COVID-19. AKI, acute kidney injury; ARDS, acute respiratory distress syndrome; ICU, intensive care unit; VTE, venous thromboembolism. Ranges are either median/interquartile range (IQR) or mean \pm standard deviation (SD)-as noted in - Tables $\mathbf{1}$ and $\mathbf{2}$. References are given in square brackets. Numbers of cases and reported $p$-values are also given in some figures.

or VWF:GPIbM assays (-Fig. 2). - Figure 2A summarizes reports identifying the level of VWF:GBIbB in cases of COVID19 versus NRRs or controls, where more than five cases of COVID-19 were reported. Like VWF:Ag, although the expected NRR for VWF:GPIbB assays would approximate 50 to $200 \mathrm{U} / \mathrm{dL}$ (or \% of normal), the literature on COVID19 again matches the general VWF literature and the reported NRR varied widely among the studies (as thus dependent on test, method, and study population) (-Tables 1 and 2). Nevertheless, in general, the upper limit of normal for VWF:GPIbB assays was again (like VWF:Ag) below $200 \mathrm{U} / \mathrm{dL}$ (or \%). In all studies, again comprising various cohorts of COVID-19 patients, median values for VWF:GPIbB assays in infected patients were always well above $200 \mathrm{U} / \mathrm{dL}$, and, indeed, so too were most of the reported lower limits of IQR or SD values (-Fig. 2A).

- Figure 2(B, C) shows additional data on VWF:GPIbB assays in COVID-19, where reports investigated a link between level of VWF and severity of COVID-19. Again, given that the studies comprised a subset of the reported VWF:Ag studies, there was similar variability in the descriptions of COVID-19 severity. In general, the level of VWF:GPIbB activi- ty was associated with severity of COVID-19, and was similar to VWF:Ag, with highest levels evident in those with "most severe" disease, as well as in nonsurvivors. Nevertheless, it should be noted that absolute levels in general were not reported to be as numerically high as those for VWF:Ag. Thus, although VWF:Ag levels were sometimes reported as above $600 \mathrm{U} / \mathrm{dL}$, those for VWF:GPIbB were not, reaching maximums closer to $400 \mathrm{U} / \mathrm{dL}$. It is unclear whether this reflects a true differential in VWF:GPIbB versus VWF:Ag in COVID-19, or is simply an artifact of the assays used, which are more often used to identify or exclude VWD (and thus the linear portion of the assay range tends to be $<100 \mathrm{U} / \mathrm{dL}){ }^{48}$

Levels of VWF collagen binding (VWF:CB) were reported only in three studies (-Fig. 2D), with mixed findings, most likely dependent on both the COVID-19 cohort and the reported VWF:CB method. For example, two studies reported on VWF:CB by chemiluminescent immunoassay (CLIA) method on the ACL AcuStar instrument, but with small numbers of COVID-19 patients $(n=6, n=10)$. Nevertheless, this method is highly discriminatory for HMW forms of VWF. $^{49}$ In contrast, one large study $(n=181)$ utilized a commercial ELISA (enzyme-linked immunosorbent assay). 
A. VWF:GPIbB assays (NRR vs COVID; $>5$ cases)

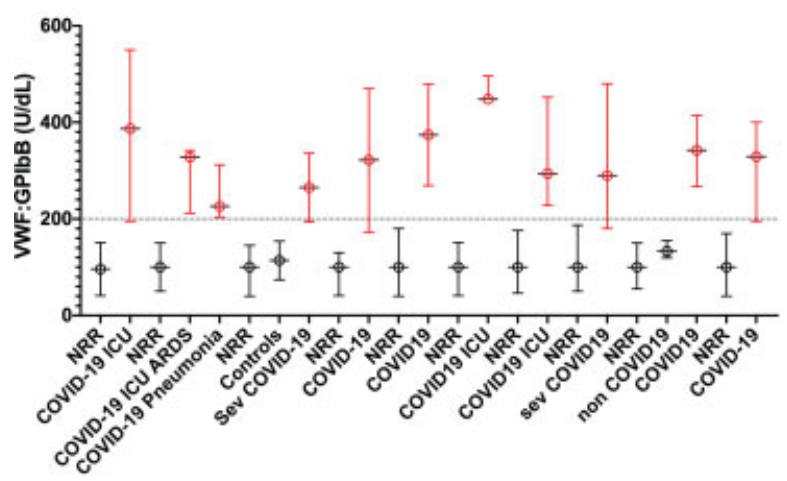

C. VWF:GPIbB assays (vs survival)

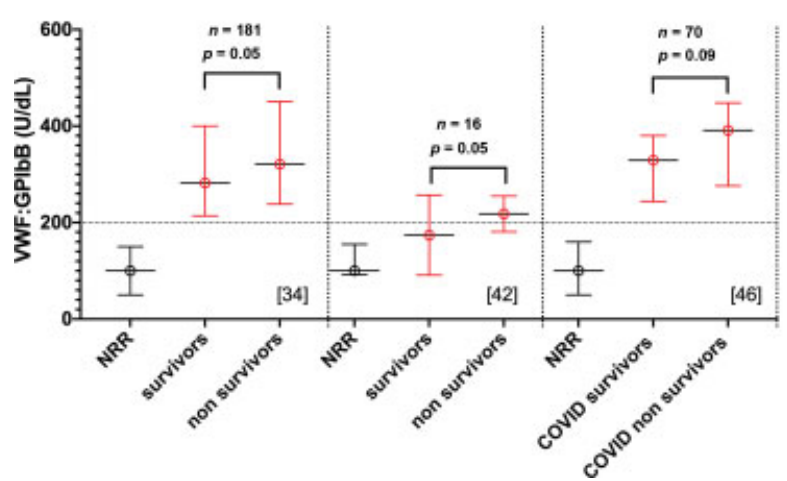

B. VWF:GPIbB assays (vs COVID 'severity')

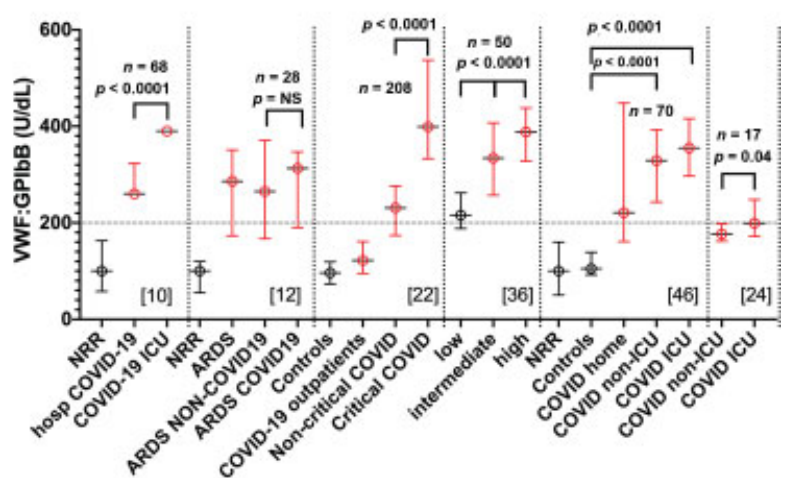

D. VWF:CB (NRR vs COVID; >5 cases)

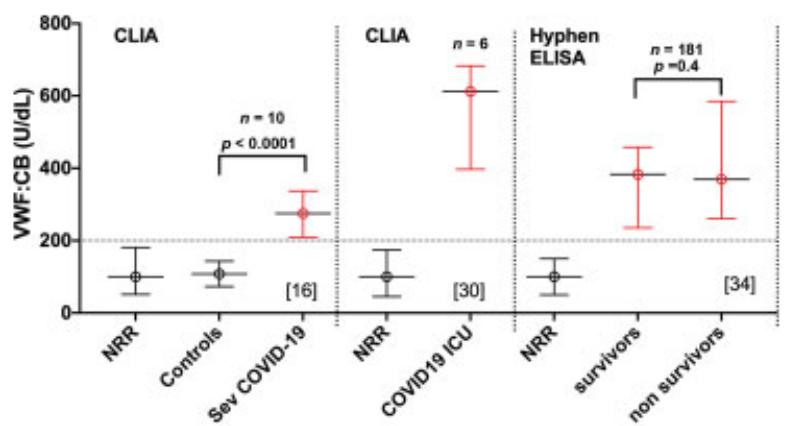

Fig. 2 Values of von Willebrand factor glycoprotein lb binding (VWF:GPIbB) or collagen binding (VWF:CB) activity reported in the literature for cases of coronavirus disease (COVID)-19, where more than five cases reported. VWF:GPIbB activity may include ristocetin cofactor [VWF:RCo] or more modern versions including VWF:GPIbR [recombinant] and VWF:GPIbM [mutant]. (A) VWF:GPIbB (left Y-axis) in U/dL (=\% of normal) for various cohorts of COVID-19 (shown in red) versus normal reference ranges (NRRs) or control groups (shown in black). In general, NRRs were around 50-200 U/dL, whereas COVID-19 cases were invariably higher, with some cases reporting >400 U/dL. (B) VWF:GPIbB (left Y-axis) in U/dL (=\% of normal) for various cohorts of COVID-19 of differing or increasing "severity." (C) VWF:GPIbB (left Y-axis) in U/dL (=\% of normal) for survivor versus nonsurvivor cohorts of COVID-19. (D) VWF:CB (left Y-axis) in U/dL (=\% of normal) for the three studies reporting levels in COVID19. ARDS, acute respiratory distress syndrome; ICU, intensive care unit. Ranges are either median/interquartile range (IQR) or mean \pm standard deviation (SD)-as noted in - Tables $\mathbf{1}$ and $\mathbf{2}$. References given in square brackets. Numbers of cases and reported $p$-values also given in some figures.

The Westmead laboratory has previously identified that commercial VWF:CB assays may vary significantly in regard to relative discrimination of HMW VWF. ${ }^{50}$

A small number of studies also reported on other VWF test parameters, such as VWF propeptide (VWFpp) ${ }^{19}$ and "active" VWF using a novel assay. ${ }^{42}$ In general, these could also be associated with COVID-19 severity. Ward et $\mathrm{al}^{19}$ reported plasma VWFpp levels were markedly elevated in severe COVID-19 (median [IQR] 325 [267-524] U/dL). Interestingly, however, they also reported that the VWFpp/VWF:Ag ratio was reduced in severe COVID-19, perhaps demonstrating that decreased VWF clearance contributes to elevated plasma VWF:Ag levels in severe COVID-19. They also reported that plasma VWFpp levels also correlated with clinical severity indices such as the Sequential Organ Failure Assessment (SOFA) score, Sepsis-Induced Coagulopathy (SIC) score, and the ratio of arterial oxygen partial pressure to fractional inspired oxygen ( $\mathrm{P} / \mathrm{F}$ ratio). Collectively, the authors concluded that these findings supported the hypothesis that sustained fulminant endothelial cell activation occurs in severe
COVID-19, and that VWFpp may have a role as a biomarker in this setting. De Jongh et $\mathrm{al}^{42}$ reported higher "active" VWF $(217.6 \pm 36.8$ vs. $173.7 \pm 83.0 ; p=0.05)$ in nonsurvivors than in survivors, using a novel method to identify "active" VWF.

\section{VWF Multimers}

VWF multimers were reported in few studies. Of interest, one system called Hydrasys permits quantification of multimers using desitometry. ${ }^{51-53}$ This system also permits numerical separation of multimers into low-molecular-weight (LMW), intermediate-molecular-weight VWF, and HMW VWF. ${ }^{51-53}$ Two studies reported results using this method in COVID-19 (-Fig. 3). 22,36 Interestingly, these reports appear to be at odds with each other. Philippe et $\mathrm{al}^{22}$ reported a comparative increase in HMW VWF and a comparative decrease in LMW VWF with critical COVID-19 (vs. "noncritical") COVID-19, as one might expect in secondary thrombotic microangiopathies expressing reduced ADAMTS-13. Conversely, and counterintuitively, Mancini et $\mathrm{al}^{36}$ reported a decreasing level of HMW VWF, as well as a reduction in HMW 


\section{VWF multimers vs COVID ( $>5$ cases)}

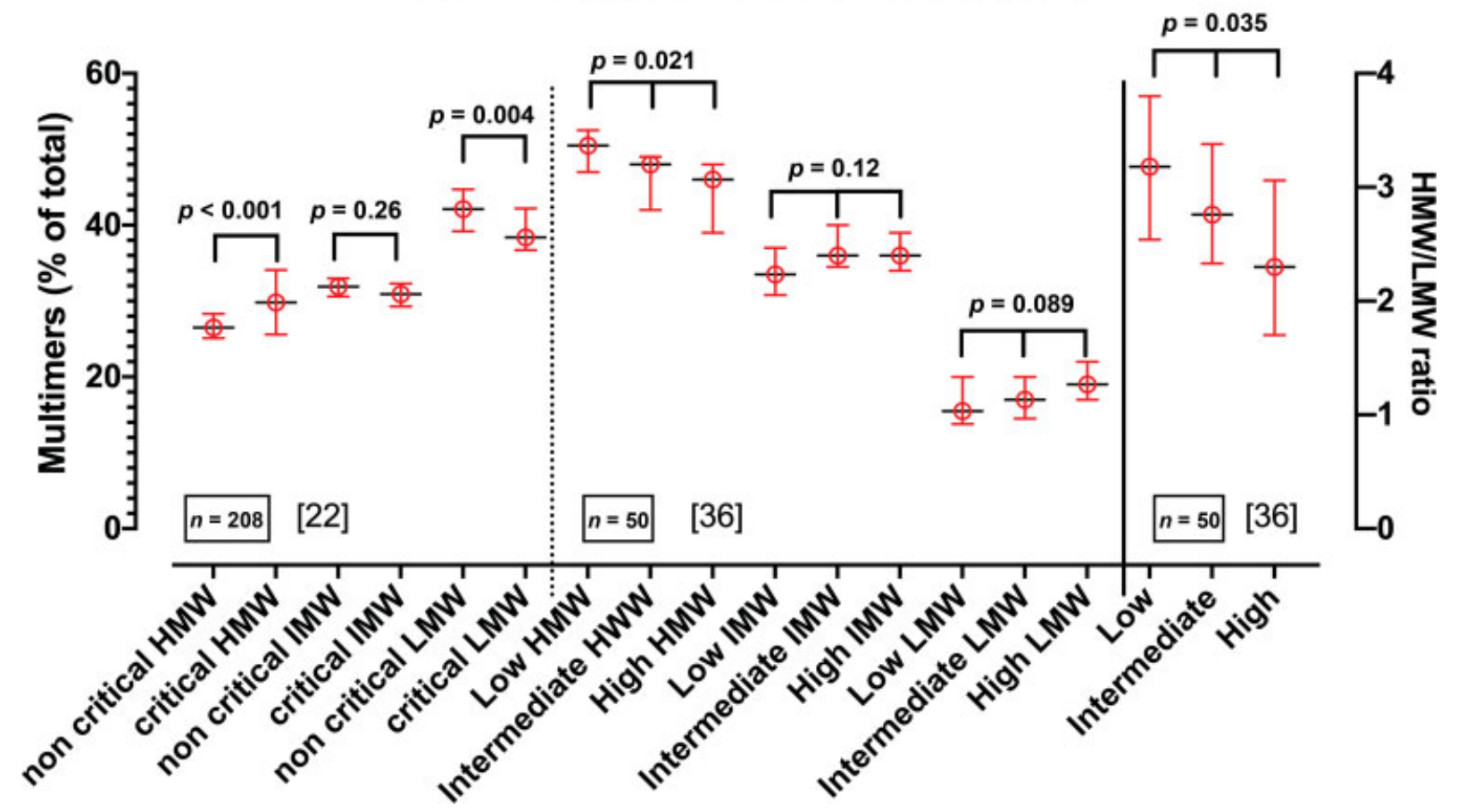

Fig. 3 Values of various fractions of von Willebrand factor (VWF) multimers reported in the literature for cases of coronavirus disease (COVID)19. VWF multimer fractions were separated into high-molecular-weight (HMW), intermediate-molecular-weight (IMW), and low-molecularweight (LMW) forms. Left Y-axis reporting as percent of total fraction (=100\%). X-axis indicates study population for COVID-19, including grade of severity. Right Y-axis identifies HMW/LMW ratio as reported in one study. Unfortunately, neither study reported the expected values for normal individuals. References given in square brackets. Numbers of cases and reported $p$-values also given.

VWF/LMW VWF ratio, with increasing severity of COVID-19. They suggested that these findings might be explained by an early increase in VWF proteolysis by ADAMTS-13, which must overcome the massive release of VWF multimers by activated endothelium as a consequence of local inflammation. Thus, differences between studies may relate to the time of testing in relation to the COVID-19 time-course. On the other hand, it can be noted that the numerical values reported seem to also differ between the studies. Thus, Philippe et $\mathrm{al}^{22}$ reported a relatively higher proportion of LMW forms ( $40 \%$ of the total) of VWF than HMW VWF ( $\sim 25-30 \%$ of the total) in test samples, whereas Mancini et $\mathrm{al}^{36}$ reported the reverse ( $\sim 20 \%$ of the total represented by LMW VWF vs. approximately 40 to $45 \%$ of the total represented by HMW VWF). This difference, given both groups reported to use the same method, needs clarification. Using this system and normal individuals, approximately $20 \%$ of the total is represented by LMW VWF while approximately 40 to $45 \%$ of the total is represented by HMW VWF, ${ }^{52}$ which more closely aligns to separations reported by Mancini et $\mathrm{al}^{36}$ for COVID-19 cases.

\section{VWF Activity/Ag Ratio}

A minority of studies also reported VWF activity/Ag ratios (-Fig. 4). These were all based on VWF:GPIbB assays ( $1 \times$ VWF:RCo, and $2 \times$ VWF:GPIbR) or a monoclonal antibodybased VWF assay (VWF:Ab). ${ }^{22,36,43,46}$ One study found increased VWF:GPIbR/Ag ratio in COVID-19-associated pneumonia versus non-COVID-19-associated pneumonia, albeit in small cohort numbers ( $n=10$ for each). ${ }^{43}$ In contrast, the other three studies did not find any statistical association of VWF activity/Ag ratios with COVID-19 severity. We could not find any study reporting on VWF:CB/Ag ratios.

\section{ADAMTS-13 Activity in COVID-19}

-Figure 5A summarizes reports identifying the level of ADAMTS-13 activity in cases of COVID-19 versus NRRs or controls, where more than five cases of COVID-19 were reported. Of interest, the expected NRR for ADAMTS-13 activity would approximate 50 to $150 \mathrm{U} / \mathrm{dL}$ (or \% of normal); however, the literature on COVID-19 (analogous to the situation with VWF) matches the general literature on ADAMTS-13 and the reported NRR varies widely based on the report (and thus the ADAMTS-13 method used; - Tables 2 and 3). Nevertheless, the lower limit of normal was generally close to $50 \mathrm{U} / \mathrm{dL}$ (or \%). In all studies, comprising various cohorts of COVID-19 patients, median values among infected patients were generally reduced compared with the expected median of the NRR (being $100 \mathrm{U} / \mathrm{dL}$ ). Moreover, the reported lower limits of IQR or SD values were almost always below $50 \mathrm{U} / \mathrm{dL}$.

- Figure $\mathbf{5}(\mathbf{B}, \mathbf{C})$ shows additional data on ADAMTS-13 activity in COVID-19, where reports investigated a link between ADAMTS-13 level and severity of COVID-19. Again, there was variability in the descriptions of COVID-19 severity in these reports, similar to the reports describing VWF parameters. The vast majority of reports indicated an 


\section{GPIbB/Ag ratio vs COVID (>5 cases)}

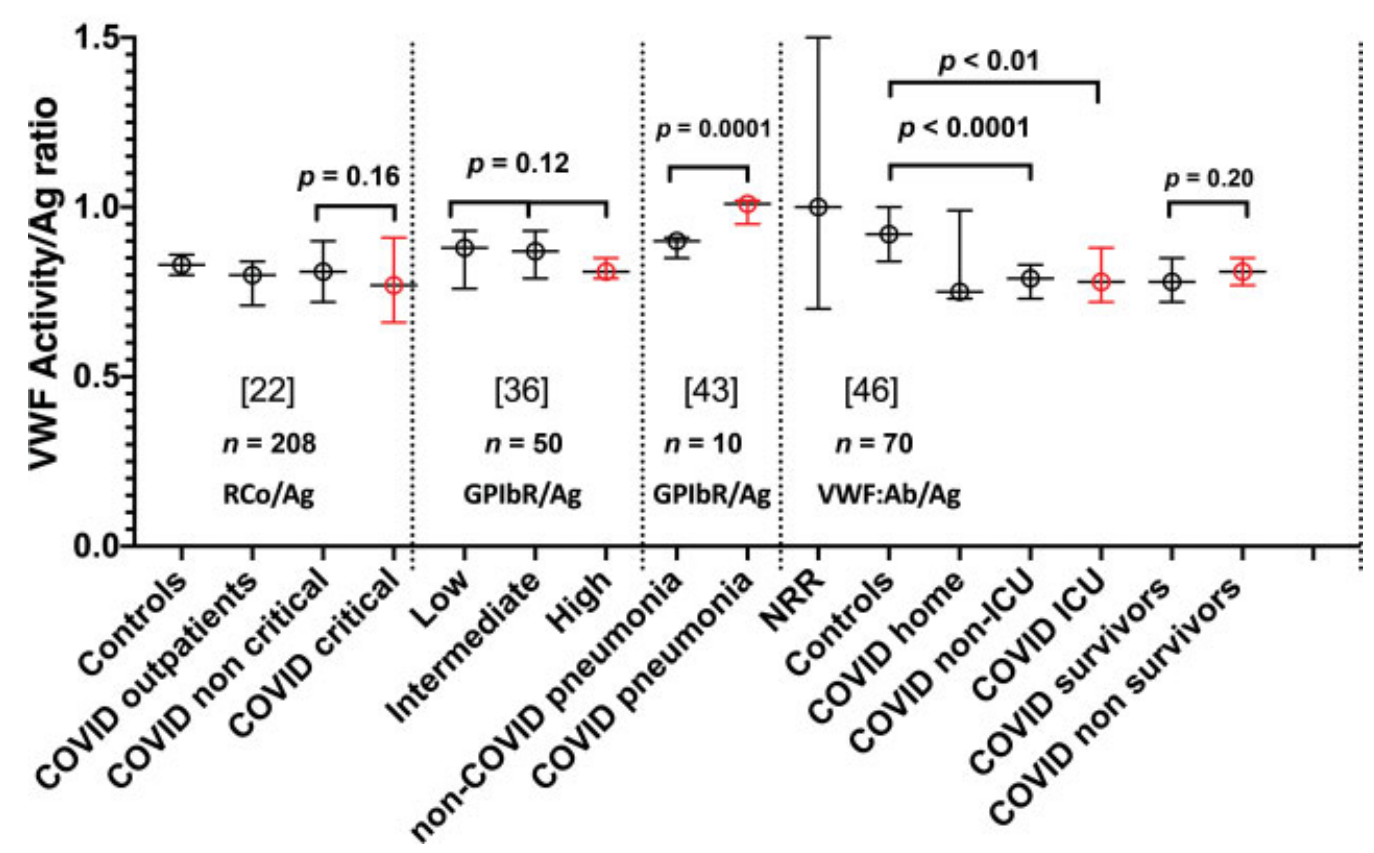

Fig. 4 Values of von Willebrand factor (VWF) activity/Ag ratios (Y-axis) reported in the literature for cases of coronavirus disease (COVID)-19, where more than five cases reported. X-axis indicates study population for COVID-19, including grade of severity. References given in square brackets. Numbers of cases and reported $p$-values are also given. NRR, normal reference range; ICU, intensive care unit.

association with COVID-19 severity, such that reduced levels of ADAMTS-13 were found in the "sickest" COVID-19 patients (-Fig. 5B) as well nonsurvivors (-Fig. 5C).

\section{VWF/ADAMTS-13 Ratio in COVID-19}

It was interesting that many studies reporting both VWF and ADAMTS-13 values also remarked on the finding of higher relative VWF/ADAMTS-13 in COVID-19 patients. However, very few studies actually provided numerical values (- Fig. 6). Invariably when reported, elevated VWF/ADAMTS13 (or reduced ADAMTS-13/VWF) ratios were found in patients with COVID-19, and these values also associated with disease severity, being the highest in those with worse illness or in nonsurvivors.

\section{Discussion}

We report on the VWF/ADAMTS-13 axis in COVID-19, characterized by a general increase in VWF level and activity, as well as by a general decrease in ADAMTS-13 activity. Values for various test parameters were also sometimes able to be associated with disease severity, including survival. Nevertheless, the literature becomes complicated because of different and sometimes diffuse definitions of "disease severity." The literature is also complicated by the use of many different assay methods, potentially leading to differing conclusions.

In general, VWF:Ag methods are "similar" in that they use antibodies against VWF to detect the level of VWF protein.
However, there are a variety of methodologies in use, including ELISA, latex immunoassay (LIA), and CLIA. Furthermore, ELISAs may be performed as in-house methods or by various commercial methods; these would use different antibodies and assay calibrators, and thus lead to somewhat differing values. LIA assays also would be provided by different manufacturers using different antibodies, assay calibrators, and instruments that will also lead to somewhat differing values. This expected variation can be evidenced, for example, by the differing NRRs reported in the literature, both for COVID-19 ( - Fig. 1A) and for VWD testing, ${ }^{48}$ although these NRRs could also be potentially reflective of differing normal populations.

VWF activity methods will differ even more than VWF:Ag assays. ${ }^{48}$ The main VWF activity generally investigated is GPIbB. In turn, this activity may be assessed by VWF:RCo assays (using platelets and ristocetin), VWF:GPIbR assays (using inert particles such as latex or magnetic beads bound to recombinant GPIb, together with ristocetin), and finally VWF:GPIbM assays (using inert particles such as latex bound to recombinant-mutated GPIb, without ristocetin). ${ }^{48}$ Thus, the NRRs for VWF:GPIbB assays would vary even more between different studies than would VWF:Ag, and accordingly so to many findings in COVID-19 patients.

ADAMTS-13 activity is also measured in many different ways, and this will also influence NRRs (- Fig. 5A), as well as values reported in COVID-19 patients. Most studies reported using FRET-based activity assays, but these were either inhouse assays or from a variety of different commercial manufacturers. Some studies reported on levels of ADAMTS-13 detected as "antigen" (i.e., not activity). 


\section{A. ADAMTS13 (usually reduced in COVID-19)}

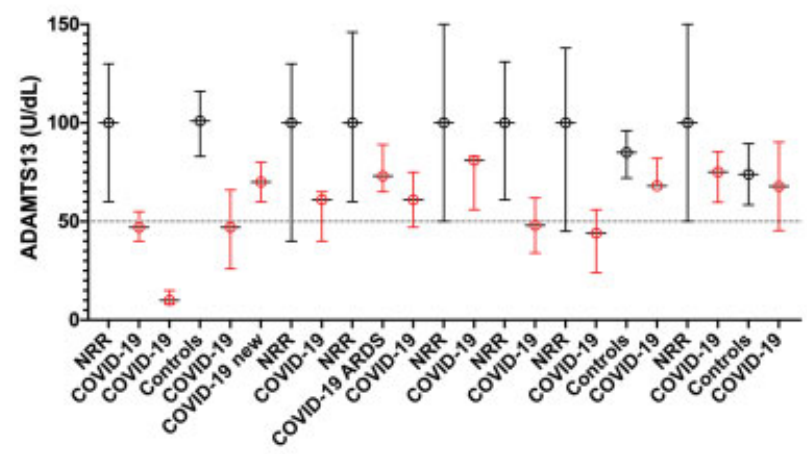

B. ADAMTS13 (vs COVID-19 severity)

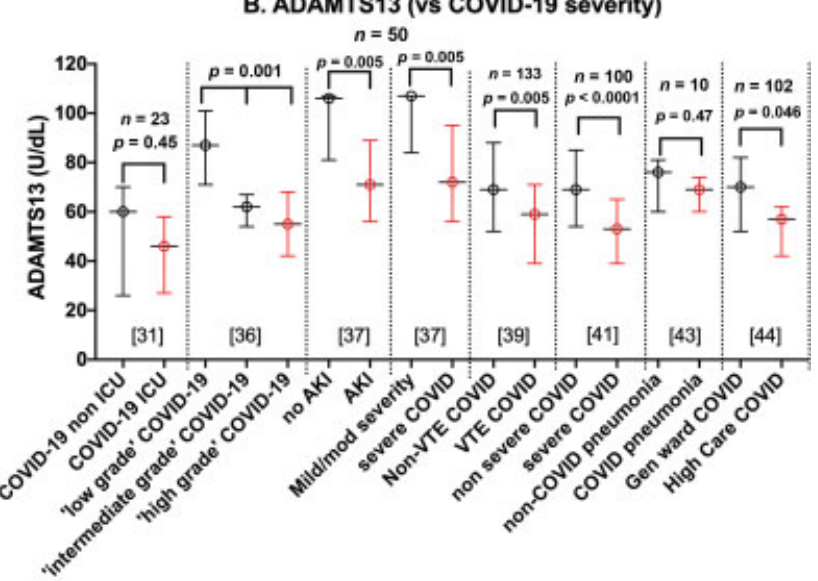

C. ADAMTS13 (vs survival)

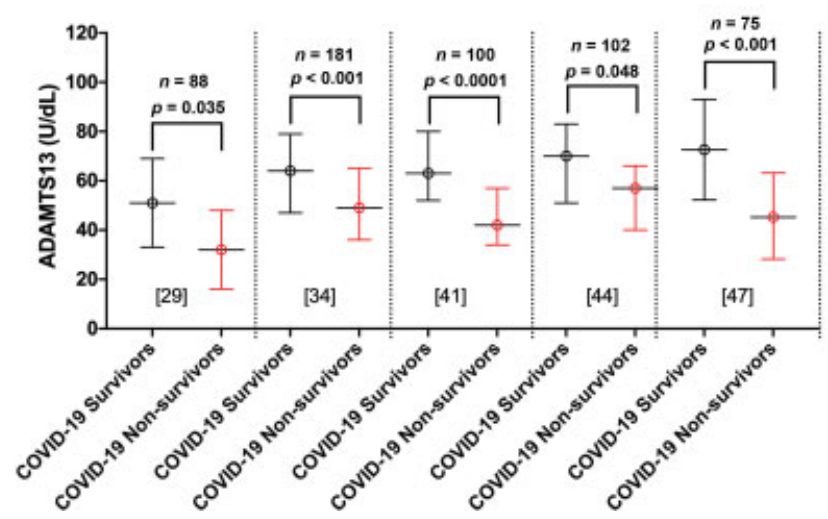

Fig. 5 Values of ADAMTS-13 activity reported in the literature for cases of coronavirus disease (COVID)-19, where more than five cases reported. (A) ADAMTS-13 activity (left Y-axis) in $\mathrm{U} / \mathrm{dL}$ ( $=\%$ of normal) for various cohorts of COVID-19 (shown in red) versus normal reference ranges (NRRs) or control groups (shown in black). In general, NRRs were around 50-150 U/dL, whereas ADAMTS-13 in COVID-19 cases was generally lower, with some cases reporting $<20 \mathrm{U} / \mathrm{dL}$. (B) ADAMTS-13 activity (left $\mathrm{Y}$-axis) in $\mathrm{U} / \mathrm{dL}$ ( $=\%$ of normal) for various cohorts of COVID-19 of differing "severity." (C) ADAMTS-13 activity (left $\mathrm{Y}$-axis) in $\mathrm{U} / \mathrm{dL}$ (=\% of normal) for survivor versus nonsurvivor cohorts of COVID-19. AKI, acute kidney injury; ARDS, acute respiratory distress syndrome; ICU, intensive care unit; VTE, venous thromboembolism. Ranges are either median/interquartile range (IQR) or mean \pm standard deviation (SD) - as noted in - Tables 2 and $\mathbf{3}$. References are given in square brackets. Numbers of cases and reported $p$-values are also given.
Perhaps relevant to the measurement of both VWF and ADAMTS-13 assays is the emergence of rapid assays by means of CLIA on the ACL AcuStar. ${ }^{49,54}$ Several studies reported on VWF and ADAMTS-13 using these methods ( - Tables 1-3), and it is likely that this technology will be increasingly used in the future.

Of interest, despite knowingly discussing raised VWF/ADAMTS-13 in COVID-19, very few studies actually reported ratio values (-Fig. 6). In essence, this was also mirrored by limited reporting of VWF activity/Ag ratios (-Fig. 4). We would therefore urge that future reports include mention of these ratio values, as this will considerably expand our understanding of the pathophysiology of COVID-19.

Irrespective of the earlier, the general increase in VWF to supranormal values in COVID-19, associated with a general decrease in ADAMTS-13 activity (even if remaining in the socalled NRR), would cause a general increase in VWF/ADAMTS-13 in the vast majority of studies, even if not numerically reported. The outcome of this increased VWF/ADAMTS-13 ratio essentially reflects an imbalance that creates a milieu that would favor (micro)thrombosis, similar to what might be seen in a secondary thrombotic microangiopathy.

In regard to thrombotic microangiopathy, the most severe form is represented by the condition of TTP, where ADAMTS13 levels fall to below $10 \mathrm{U} / \mathrm{dL}$ (or \%), although TTP may also be diagnosed where cases have ADAMTS- 13 between 10 and $20 \mathrm{U} / \mathrm{dL}^{54}$ Very few reports in the literature actually report TTP in COVID-19. Most reports of COVID-19 report only moderately reduced levels of ADAMTS-13 (-Fig. 5). Nevertheless, TTP or TTP-like syndromes have been reported in COVID-19. For example, Alharthy et $\mathrm{al}^{27}$ reported a small case series of three cases of severe COVID-19 in which ADAMTS- 13 was $\leq 15 \mathrm{U} / \mathrm{dL}(\%)$. The patients were also reported to have antiphospholipid antibodies and presented clinically with stroke (brain infarction), respiratory distress syndrome, and pulmonary embolism. They were treated with plasma exchange, a treatment commonly applied in TTP, and patients improved clinically and gradually recovered neurologically (after 27-32 days). Another interesting case series was presented by Arulkumaran et $\mathrm{al}^{38}$ who utilized plasma exchange in seven severely critical COVID19 patients with acute respiratory distress syndrome (ARDS) versus seven matched controls, and who not only showed improvement in patients after plasma exchange but also noted that five of seven controls developed AKI, whereas AKI was developed in none of the seven plasma-exchangetreated patients. The reported ADAMTS-13 levels in this case series were normal (median, 73 [IQR, 65-89] U/dL), but the median VWF/ADAMTS-13 ratio was high (4.0 [IQR, 2.8-5.7]). Thus, a therapy utilized in TTP may still have therapeutic success in COVID-19 without evidence of TTP. Finally, we can highlight the report from Doevelaar et al, ${ }^{47}$ who concluded from their study that "COVID-19 is associated with a substantial increase in VWF levels, which can exceed the ADAMTS-13-processing capacity, resulting in the formation of large VWF multimers indistinguishable from TTP." 


\section{VWFIADAMTS13 (increased in COVID-19)}

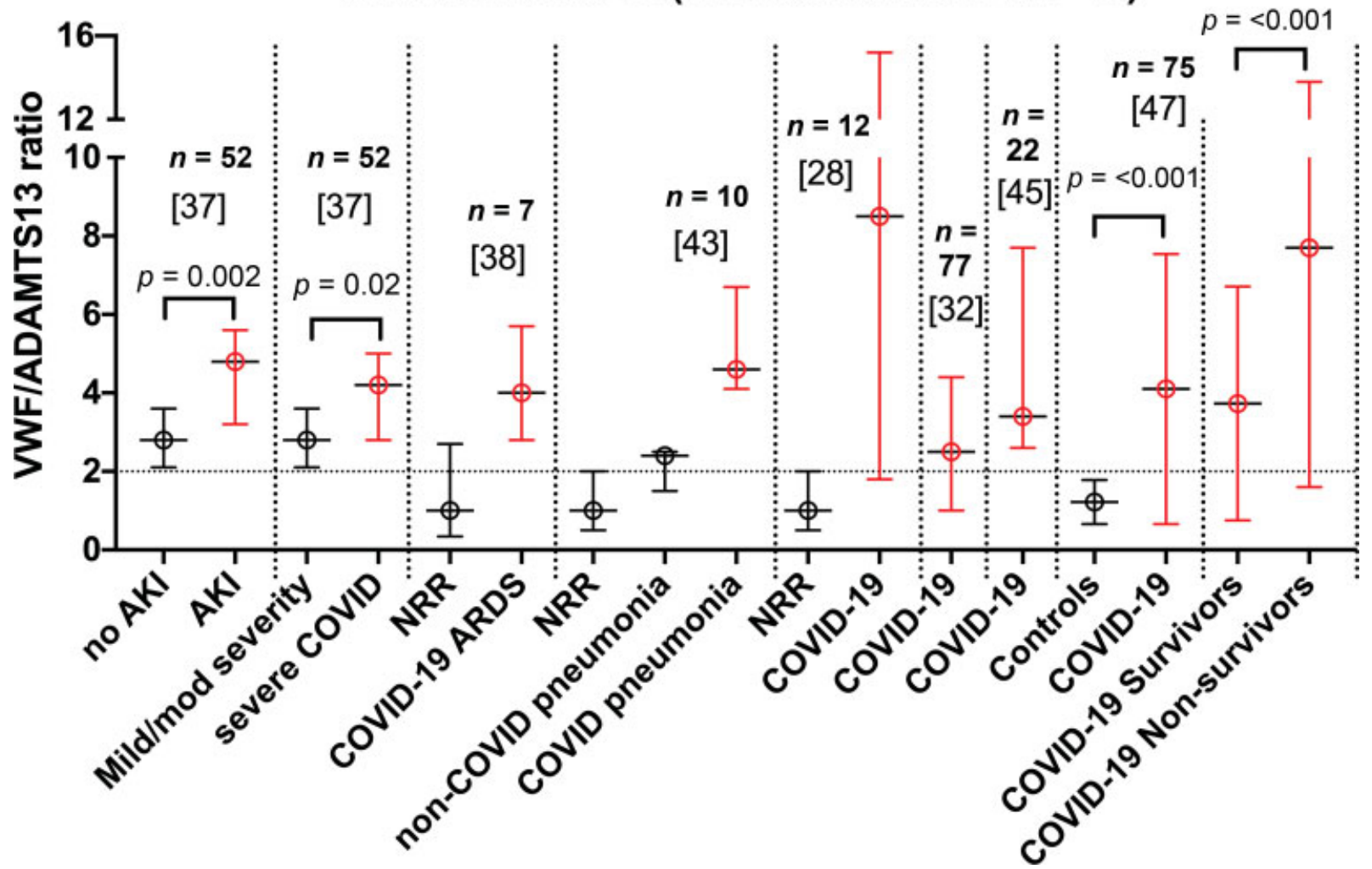

Fig. 6 Values of von Willebrand factor (VWF)/ADAMTS-13 ratio (Y-axis), as reported in the literature for cases of coronavirus disease (COVID)-19, where more than five cases reported. X-axis indicates study population for COVID-19, including grade of severity. References are given in square brackets. Numbers of cases and reported $p$-values are also given. Data have been converted to VWF/ADAMTS-13 where report gives as ADAMTS13/VWF. AKI, acute kidney injury; ARDS, acute respiratory distress syndrome; NRR, normal reference range.

They investigated 75 patients with COVID-19 of varied severity versus 30 healthy controls. VWF:Ag in cases was high (mean \pm SD: $403 \pm 218$ vs. $99 \pm 31 \mathrm{U} / \mathrm{dL} ; p<0.001$ ). ADAMTS-13 levels in cases were only moderately (but not statistically) reduced $(67.8 \pm 22.4$ vs. $73.9 \pm 15.5 \mathrm{U} / \mathrm{dL}$; $p=0.176)$. The ADAMTS- $13 / \mathrm{VWF}$ ratio was significantly reduced $(0.244 \pm 20.5$ vs. $0.820 \pm 0.307 \mathrm{U} / \mathrm{dL} ; p<0.001$, which is equivalent to a raised VWF/ADAMTS-13 ratio). Nevertheless, they also reported that large multimers in COVID-19 patients were significantly lower than in healthy pool samples $(68.69 \pm 16.16 \% \quad$ vs. $\quad 112.04 \pm 13.31 \%$; $p<0.0001$ ), which is counter-intuitive to what one may expect, but in essence similar to the finding reported by Mancini et al. $^{36}$ Such findings need future clarification, and appear to be at odds with the findings of Philippe et $\mathrm{al}^{22}$ (as previously noted), who reported a higher proportion of HMW VWF in patients with critical COVID-19.

The number of cases as reported is another complication in the literature. We specifically excluded individual or small cases series $(\leq 5)$ in our review of the literature shown in -Figs. 1-5 to 6, but even the evaluated dataset had a significant variability in their sample size. Naturally, the larger the number, the more assurance on the findings.

A final complication of the literature that we will highlight is the disparity in reporting ranges and methods. Most studies reported study ranges as median/IQR; however, many alternatively reported mean/SD. A great variety of
VWF and ADAMTS-13 methods were also employed. Sometimes, methods could not be identified. We highlight the variety of methods has implications in regard to commutability of results. As an example, different methods yield different NRRs due to method and calibrator disparity. Different NRRs also imply different results would be expected between different methods for COVID-19 cases. The situation for VWF and ADAMTS-13 is in some respects similar to that previously raised for D-dimer. ${ }^{55}$ We thus make the same call for investigators in the field to clearly report the methods utilized in future studies. We also call for investigators to report both $\mathrm{VWF}$ activity/Ag ratios and VWF/ADAMTS-13 ratios in future reports.

\section{Conclusion}

In summary, the current evidence strongly suggests that COVID-19 can progress toward a thrombotic disorder, characterized by both micro- and macrothrombosis in the lungs, as well as in many other organs and tissues. ${ }^{56-59}$ The development of any form of thrombosis will have a strong impact on a patient's prognosis, and appears in all severe COVID-19 patients to be accompanied by an imbalance of VWF and ADAMTS-13 resulting in a high VWF/ADAMTS-13 ratio. This may also pave the way to assessing specific therapies already used in secondary thrombotic microangiopathies, such as plasma exchange and complement 
Table 3 Summary of literature related to VWF and ADAMTS-13 in COVID-19-Part III: (lowered) ADAMTS-13 ${ }^{\mathrm{a}}$

\begin{tabular}{|c|c|c|c|c|c|}
\hline Reference citation & $\begin{array}{l}\text { Case descriptions and main } \\
\text { findings }\end{array}$ & $\begin{array}{l}\text { Number } \\
\text { of COVID-19 } \\
\text { cases }\end{array}$ & Data reporting & $\begin{array}{l}\text { Method for } \\
\text { ADAMTS-13 }\end{array}$ & $\begin{array}{l}\text { Link to COVID-19 } \\
\text { severity }\end{array}$ \\
\hline Martinelli et al ${ }^{25}$ & $\begin{array}{l}\text { Mild reduction of ADAMTS- } \\
13 \text { activity ( } 47 \text { [40-55], nor- } \\
\text { mal range: } 60-130) \text { identi- } \\
\text { fied in } 13 \text { patients with } \\
\text { COVID-19 hospitalized for } \\
\text { respiratory symptoms with a } \\
\text { chest X-ray compatible with } \\
\text { bilateral interstitial } \\
\text { pneumonia }\end{array}$ & 13 & Median? 95\% Cl & $\begin{array}{l}\text { ADAMTS-13 } \\
\text { method not } \\
\text { specified }\end{array}$ & Not evaluated \\
\hline Rovas et $\mathrm{al}^{26}$ & $\begin{array}{l}23 \text { hospitalized adult patients } \\
\text { with moderate-to-severe or } \\
\text { critical COVID-19. ADAMTS-13 } \\
\text { decreased significantly with } \\
\text { increasing COVID-19 severity } \\
\text { (mechanical ventilation). } \\
\text { Reduced ADAMTS-13 also } \\
\text { associated with 60-day } \\
\text { mortality }\end{array}$ & 23 & $\begin{array}{l}\text { ADAMTS-13 } \\
\text { reported in } \\
\text { arbitrary units }\end{array}$ & $\begin{array}{l}\text { ADAMTS-13 } \\
\text { (multiplex assay) }\end{array}$ & $\begin{array}{l}\text { ADAMTS-13 } \\
\text { decreased } \\
\text { significantly with } \\
\text { increasing } \\
\text { COVID-19 } \\
\text { severity } \\
\text { (mechanical } \\
\text { ventilation). } \\
\text { Reduced } \\
\text { ADAMTS-13 } \\
\text { also associated } \\
\text { with 60-day } \\
\text { mortality }\end{array}$ \\
\hline
\end{tabular}

Abbreviation: ADAMTS-13, a disintegrin and metalloproteinase with a thrombospondin type 1 motif, member 13; COVID, coronavirus disease; VWF, von Willebrand factor.

aData exclude single case studies, and listed in order of PubMed listing. Note that wide variety of methods (not always documented) may be used to assess ADAMTS-13. This will have an influence on findings, but this is not always understood by authors who report on findings. Values reported in $\mathrm{U} / \mathrm{dL}(=\%)$.

inhibitors (e.g., eculizumab). Preliminary data suggest that use of complement inhibitors may be effective to improve survival and for reducing hypoxia, especially in COVID-19 patients with severe illness and/or ARDS. ${ }^{60-62}$ Similar promising results have been reported with plasma exchange. ${ }^{38}$ These findings all suggest that secondary thrombotic microangiopathy may be a major driver of outcomes in SARS-CoV2 infection, such that its attenuation by therapies already used in the treatment of thrombotic microangiopathy would appear a reasonable strategy.

Nevertheless, further research is needed to fully understand the mechanisms associated with the prothrombotic state in COVID-19, including how the VWF/ADAMTS-13 axis imbalance connects to the intermingled mechanisms of SARS-CoV-2 pathophysiology, such as immune dysregulation, complement overactivation, neutrophil extracellular traps, and autoantibodies, which may all converge to propagate COVID-19-associated coagulopathy. ${ }^{56}$

Also, there needs to be improved reporting of VWF and ADAMTS-13 methodologies, which were not always described by researchers. This may be facilitated by a better understanding of how different VWF and ADAMTS-13 methodologies may lead to different NRRs and different values in COVID-19, and thus each study is not necessarily commutable to another study.

Conflict of Interest

None declared.

\section{References}

1 Yee A, Kretz CA. Von Willebrand factor: form for function. Semin Thromb Hemost 2014;40(01):17-27

2 Favaloro EJ, Pasalic L, Curnow J. Monitoring therapy during treatment of von Willebrand disease. Semin Thromb Hemost 2017;43(03):338-354

3 Calabrò P, Gragnano F, Golia E, Grove EL. von Willebrand factor and venous thromboembolism: pathogenic link and therapeutic implications. Semin Thromb Hemost 2018;44(03):249-260

4 Blennerhassett R, Curnow J, Pasalic L. Immune-mediated thrombotic thrombocytopenic purpura: a narrative review of diagnosis and treatment in adults. Semin Thromb Hemost 2020;46(03): 289-301

5 Aigner C, Schmidt A, Gaggl M, Sunder-Plassmann G. An updated classification of thrombotic microangiopathies and treatment of complement gene variant-mediated thrombotic microangiopathy. Clin Kidney J 2019;12(03):333-337

6 Favaloro EJ, Henry BH, Lippi G. VWF and ADAMTS13 in COVID-19 and beyond: a question of balance. 2021; in press

7 Panigada M, Bottino N, Tagliabue P, et al. Hypercoagulability of COVID-19 patients in intensive care unit: a report of thromboelastography findings and other parameters of hemostasis. J Thromb Haemost 2020;18(07):1738-1742

8 Poissy J, Goutay J, Caplan M, et al; Lille ICU Haemostasis COVID-19 Group. Pulmonary embolism in patients with COVID-19: awareness of an increased prevalence. Circulation 2020;142(02): 184-186

9 Helms J, Tacquard C, Severac F, et al; CRICS TRIGGERSEP Group (Clinical Research in Intensive Care and Sepsis Trial Group for Global Evaluation and Research in Sepsis) High risk of thrombosis in patients with severe SARS-CoV-2 infection: a multicenter prospective cohort study. Intensive Care Med 2020;46(06): 1089-1098 
10 Goshua G, Pine AB, Meizlish ML, et al. Endotheliopathy in COVID19-associated coagulopathy: evidence from a single-centre, cross-sectional study. Lancet Haematol 2020;7(08):e575-e582

11 Ladikou EE, Sivaloganathan H, Milne KM, et al. Von Willebrand factor (vWF): marker of endothelial damage and thrombotic risk in COVID-19? Clin Med (Lond) 2020;20(05):e178-e182

12 Masi P, Hékimian G, Lejeune M, et al. Systemic inflammatory response syndrome is a major contributor to COVID-19-associated coagulopathy: insights from a prospective, single-center cohort study. Circulation 2020;142(06):611-614

13 Sardu C, Marfella R, Maggi P, et al. Implications of ABO blood group in hypertensive patients with covid-19. BMC Cardiovasc Disord 2020;20(01):373

14 Rauch A, Labreuche J, Lassalle F, et al. Coagulation biomarkers are independent predictors of increased oxygen requirements in COVID-19. J Thromb Haemost 2020;18(11):2942-2953

15 Hoechter DJ, Becker-Pennrich A, Langrehr J, et al. Higher procoagulatory potential but lower DIC score in COVID-19 ARDS patients compared to non-COVID-19 ARDS patients. Thromb Res 2020; 196:186-192

16 Taus F, Salvagno G, Canè $S$, et al. platelets promote thromboinflammation in SARS-CoV-2 pneumonia. Arterioscler Thromb Vasc Biol 2020;40(12):2975-2989

17 Fan BE, Ng J, Chan SSW, et al. COVID-19 associated coagulopathy in critically ill patients: a hypercoagulable state demonstrated by parameters of haemostasis and clot waveform analysis. J Thromb Thrombolysis 2021;51(03):663-674

18 Cugno M, Meroni PL, Gualtierotti R, et al. Complement activation and endothelial perturbation parallel COVID-19 severity and activity. J Autoimmun 2021;116:102560

19 Ward SE, Curley GF, Lavin M, et al; Irish COVID-19 Vasculopathy Study (ICVS) Investigators. Von Willebrand factor propeptide in severe coronavirus disease 2019 (COVID-19): evidence of acute and sustained endothelial cell activation. Br J Haematol 2021;192 (04):714-719

20 Ruberto F, Chistolini A, Curreli M, et al; Policlinico Umberto I COVID-19 Group. Von Willebrand factor with increased binding capacity is associated with reduced platelet aggregation but enhanced agglutination in COVID-19 patients: another COVID19 paradox? J Thromb Thrombolysis 2021 (epub ahead of print). Doi: $10.1007 / \mathrm{s} 11239-020-02339-6$

21 Heinz C, Miesbach W, Herrmann E, et al. Greater fibrinolysis resistance but no greater platelet aggregation in critically ill COVID-19 patients. Anesthesiology 2021;134(03):457-467

22 Philippe A, Chocron R, Gendron N, et al. Circulating Von Willebrand factor and high molecular weight multimers as markers of endothelial injury predict COVID-19 in-hospital mortality. Angiogenesis 2021 (epub ahead of print). Doi: 10.1007/s10456-02009762-6

23 Vassiliou AG, Keskinidou C, Jahaj E, et al. ICU admission levels of endothelial biomarkers as predictors of mortality in critically ill COVID-19 patients. Cells 2021;10(01):186

24 Bauer W, Galtung N, Neuwinger N, et al. A matter of caution: coagulation parameters in COVID-19 do not differ from patients with ruled-out SARS-CoV-2 infection in the emergency department. TH Open 2021;5(01):e43-e55

25 Martinelli N, Montagnana M, Pizzolo F, et al. A relative ADAMTS13 deficiency supports the presence of a secondary microangiopathy in COVID 19. Thromb Res 2020;193:170-172

26 Rovas A, Osiaevi I, Buscher K, et al. Microvascular dysfunction in COVID-19: the MYSTIC study. Angiogenesis 2021;24(01): 145-157

27 Alharthy A, Faqihi F, Balhamar A, Memish ZA, Karakitsos D. Lifethreatening COVID-19 presenting as stroke with antiphospholipid antibodies and low ADAMTS-13 activity, and the role of therapeutic plasma exchange: a case series. SAGE Open Med Case Rep 2020; (epub ahead of print) . Doi: 10.1177/2050313X20964089
28 Huisman A, Beun R, Sikma M, Westerink J, Kusadasi N. Involvement of ADAMTS13 and von Willebrand factor in thromboembolic events in patients infected with SARS-CoV-2. Int J Lab Hematol 2020;42(05):e211-e212

29 Bazzan M, Montaruli B, Sciascia S, Cosseddu D, Norbiato C, Roccatello D. Low ADAMTS 13 plasma levels are predictors of mortality in COVID-19 patients. Intern Emerg Med 2020;15(05): 861-863

30 Morici N, Bottiroli M, Fumagalli R, Marini C, Cattaneo M. Role of von Willebrand factor and ADAMTS-13 in the pathogenesis of thrombi in SARS-CoV-2 infection: time to rethink. Thromb Haemost 2020;120(09):1339-1342

31 Blasi A, von Meijenfeldt FA, Adelmeijer J, et al. In vitro hypercoagulability and ongoing in vivo activation of coagulation and fibrinolysis in COVID-19 patients on anticoagulation. J Thromb Haemost 2020;18(10):2646-2653

32 Tiscia GL, Favuzzi G, De Laurenzo A, et al; CSS COVID-19 Group. Reduction of ADAMTS13 levels predicts mortality in SARS-CoV-2 patients. TH Open 2020;4(03):e203-e206

33 Fraser DD, Patterson EK, Slessarev M, et al. Endothelial injury and glycocalyx degradation in critically ill coronavirus disease 2019 patients: implications for microvascular platelet aggregation. Crit Care Explor 2020;2(09):e0194

34 Sweeney JM, Barouqa M, Krause GJ, Gonzalez-Lugo JD, Rahman S, Gil MR. Evidence for secondary thrombotic microangiopathy in COVID-19. medRxiv 2020 (epub ahead of print). Doi: $10.1101 / 2020.10 .20 .20215608$

35 Hardy M, Michaux I, Lessire S, et al. Prothrombotic hemostasis disturbances in patients with severe COVID-19: individual daily data. Data Brief 2020;33:106519

36 Mancini I, Baronciani L, Artoni A, et al. The ADAMTS13-von Willebrand factor axis in COVID-19 patients. J Thromb Haemost 2021;19(02):513-521

37 Henry BM, Benoit SW, de Oliveira MHS, Lippi G, Favaloro EJ, Benoit JL. ADAMTS13 activity to von Willebrand factor antigen ratio predicts acute kidney injury in patients with COVID-19: Evidence of SARS-CoV-2 induced secondary thrombotic microangiopathy. Int J Lab Hematol 2020 (epub ahead of print). Doi: 10.1111/ijlh.13415

38 Arulkumaran N, Thomas M, Brealey D, et al. Plasma exchange for COVID-19 thrombo-inflammatory disease. EJHaem 2020 (epub ahead of print). Doi: 10.1002/jha2.140

39 Delrue $M$, Siguret V, Neuwirth $M$, et al. von Willebrand factor/ADAMTS13 axis and venous thromboembolism in moderate-to-severe COVID-19 patients. Br J Haematol 2021;192(06): 1097-1100

40 Fernández-Pérez MP, Águila S, Reguilón-Gallego L, et al. Neutrophil extracellular traps and von Willebrand factor are allies that negatively influence COVID-19 outcomes. Clin Transl Med 2021; 11(01):e268

41 Rodríguez Rodríguez M, Castro Quismondo N, Zafra Torres D, Gil Alos D, Ayala R, Martinez-Lopez J. Increased von Willebrand factor antigen and low ADAMTS13 activity are related to poor prognosis in covid-19 patients. Int J Lab Hematol 2021 (ePub ahead of print). Doi: $10.1111 /$ ijlh.13476

42 De Jongh R, Ninivaggi M, Mesotten D, et al. Vascular activation is a strong predictor of mortality in coronavirus disease 2019 patients on the ICU. Blood Coagul Fibrinolysis 2021 (epub ahead of print). Doi: 10.1097/MBC.0000000000001007

43 De Cristofaro R, Liuzzo G, Sacco M, Lancellotti S, Pedicino D, Andreotti F. Marked von Willebrand factor and factor VIII elevations in severe acute respiratory syndrome coronavirus-2positive, but not severe acute respiratory syndrome coronavirus-2negative, pneumonia: a case-control study. Blood Coagul Fibrinolysis 2021 (epub ahead of print). Doi: 10.1097/ MBC.0000000000000998

44 von Meijenfeldt FA, Havervall S, Adelmeijer J, et al. Prothrombotic changes in patients with COVID-19 are associated with disease 
severity and mortality. Res Pract Thromb Haemost 2020;5(01): 132-141

45 Falter T, Rossmann H, Menge P, et al. No evidence for classic thrombotic microangiopathy in COVID-19. J Clin Med 2021;10 (04):671

46 Pascreau T, Zia-Chahabi S, Zuber B, Tcherakian C, Farfour E, Vasse M. ADAMTS 13 deficiency is associated with abnormal distribution of von Willebrand factor multimers in patients with COVID19. Thromb Res 2021; (epub ahead of print) . Doi: 10.1016/j. thromres.2021.02.008

47 Doevelaar AAN, Bachmann M, Hölzer B, et al. von Willebrand factor multimer formation contributes to immunothrombosis in coronavirus disease 2019. Crit Care Med 2021;49(05): e512-e520

48 Favaloro EJ. Navigating the myriad of von Willebrand factor assays. Hamostaseologie 2020;40(04):431-442

49 Favaloro EJ, Mohammed S. Evaluation of a von Willebrand factor three test panel and chemiluminescent-based assay system for identification of, and therapy monitoring in, von Willebrand disease. Thromb Res 2016;141:202-211

50 Favaloro EJ. Evaluation of commercial von Willebrand factor collagen binding assays to assist the discrimination of types 1 and 2 von Willebrand disease. Thromb Haemost 2010;104(05): 1009-1021

51 Oliver S, Vanniasinkam T, Mohammed S, Vong R, Favaloro EJ. Semi-automated von Willebrand factor multimer assay for von Willebrand disease: further validation, benefits and limitations. Int J Lab Hematol 2019;41(06):762-771

52 Favaloro EJ. Classification of von Willebrand disease in the context of modern contemporary von Willebrand factor testing methodologies. Res Pract Thromb Haemost 2020;4(06):952-957

53 Favaloro EJ, Oliver S, Mohammed S, Vong R. Comparative assessment of von Willebrand factor multimers vs activity for von
Willebrand disease using modern contemporary methodologies. Haemophilia 2020;26(03):503-512

54 Favaloro EJ, Mohammed S, Chapman K, et al. A multicenter laboratory assessment of a new automated chemiluminescent assay for ADAMTS13 activity. J Thromb Haemost 2021;19(02): 417-428

55 Favaloro EJ, Thachil J. Reporting of D-dimer data in COVID-19: some confusion and potential for misinformation. Clin Chem Lab Med 2020;58(08):1191-1199

56 Lippi G, Sanchis-Gomar F, Favaloro EJ, Lavie CJ, Henry BM. Coronavirus disease 2019-associated coagulopathy. Mayo Clin Proc 2021;96(01):203-217

57 Levi M, Thachil J. Coronavirus disease 2019 coagulopathy: disseminated intravascular coagulation and thrombotic microangiopathy-either, neither, or both. Semin Thromb Hemost 2020;46 (07):781-784

58 Thachil J, Srivastava A. SARS-2 coronavirus-associated hemostatic lung abnormality in COVID-19: Is it pulmonary thrombosis or pulmonary embolism? Semin Thromb Hemost 2020;46(07):777-780

59 Schulman S. Coronavirus disease 2019, prothrombotic factors, and venous thromboembolism. Semin Thromb Hemost 2020;46 (07):772-776

60 Annane D, Heming N, Grimaldi-Bensouda L, et al; Garches COVID 19 Collaborative Group. Eculizumab as an emergency treatment for adult patients with severe COVID-19 in the intensive care unit: a proof-of-concept study. EClinicalMedicine 2020;28:100590

61 Laurence J, Mulvey JJ, Seshadri M, et al. Anti-complement C5 therapy with eculizumab in three cases of critical COVID-19. Clin Immunol 2020;219:108555

62 Giudice V, Pagliano P, Vatrella A, et al. Combination of ruxolitinib and eculizumab for treatment of severe SARS-CoV-2-related acute respiratory distress syndrome: a controlled study. Front Pharmacol 2020;11:857 